\title{
Rural-urban gradient and land use in a millenary metropolis: how urbanization affects avian functional groups and the role of old villas in bird assemblage patterning
}

\author{
L. Vignoli ${ }^{1,2}$, S. Scirè ${ }^{1}$, and M. A. Bologna ${ }^{1}$ \\ ${ }^{1}$ Dipartimento di Scienze, Università Roma Tre. Viale G. Marconi, 446, 00146 Rome, Italy \\ ${ }^{2}$ Center for Evolutionary Ecology, Largo San Leonardo Murialdo, 1, 00146 Rome, Italy
}

Correspondence to: L. Vignoli (leonardo.vignoli@uniroma3.it)

Received: 31 August 2012 - Revised: 9 June 2013 - Accepted: 11 June 2013 - Published: 8 July 2013

\begin{abstract}
Urbanization generally leads to a complex environmental gradient, ranging from almost undisturbed natural areas to highly modified urban landscapes. Here we analyse the effects of a rural-urban gradient on breeding bird communities and functional species groups in remnant natural and semi-natural areas of Rome. A total of 69 breeding bird species were found in the study area. Species richness decreased with increasing urbanization at two spatial scales: the point count station and the landscape scales. Evenness showed a negative trend from periphery to city centre, whereas for dominant species the opposite was true. Functional species groups responded to the urbanization gradient with functional group-specific patterns. Those groups linked to open habitats (nesting and habitat functional groups) decreased in abundance along the rural-urban gradient, whereas those associated with forests exhibited a mixed trend. Generalist species' occurrence increased with urbanization. As for predators and granivorous species, we found a negative relationship with urbanization whereas for omnivorous species the opposite trend was true. The distribution of old villas (largesized remnant green areas) in the inner city areas influenced species composition along the studied gradient, usually showing higher species richness than surrounding fragments. Agricultural areas hosted richer and better balanced bird assemblages in respect to those found in urban and forested areas. Our findings proved that an urban gradient plays a major role in structuring bird communities, although the extent and distribution of land use categories was another factor that influenced avian assemblages. The presence of historical villas also influenced bird assemblages, making it possible to preserve high bird diversity even in inner city-areas.
\end{abstract}

1

Urbanization can have a drastic effect on natural and seminatural habitats. Recent progress in this field notwithstanding, our understanding about the consequences of such an effect still needs improvement (Alberti, 2005; Chace and Walsh, 2006; McDonnell and Hahs, 2008; Berland, 2012; Pellissier et al., 2012). Studying the effects of urbanization on bird communities has been a research field since 1950 (Marzluff, 2001). Most studies of urban bird communities have reported that species richness generally decreases with urbanization and that total avian density or biomass gener- ally increases (Lancaster and Rees, 1979; Aldrich and Coffin, 1980; Beissenger and Osborne, 1982; Mills et al., 1989; Cam et al., 2000; Clergeau et al., 2006a). Urban landscapes, especially in European towns dating back to the Middle Ages, often comprise a dense, highly developed core surrounded by irregular rings of diminishing development (McDonnell and Hahs, 2008). Usually, this pattern of urbanization gives rise to a complex environmental gradient, ranging from undisturbed natural areas to highly modified urban landscapes. Such a gradient can be useful in exploring relationships between different levels of urbanization and the diversity and abundance of species (Matson, 1990; McDonnell 
and Pickett, 1990; McDonnell et al., 1993, 1997; Melles et al., 2003; Crooks et al., 2004; McDonnell and Hahs, 2008). Large metropolitan areas may represent a peak of urbanization, even though they may include remnant green areas of variable sizes. The Municipality of Rome, Central Italy, is one of the western metropolitan areas with the highest proportion of green spaces $(67 \%)$, half of these being protected areas (Vignoli et al., 2009). Rome's millennial-old natural heritage includes an extraordinary high number of old villas, most deriving from the enclosure of the Roman countryside and estates, mainly located within the inner city area. The presence and the distribution of such different typologies of remnant green areas make Rome a patchwork of seminatural vs. man-made environments that can be used as a good model for analysing the effect of urbanization in its most pronounced form (Vignoli et al., 2009).

The discovery and interpretation of significant ecosystem processes have found a valuable tool in the functional group approach (e.g. Díaz and Cabido, 2001; French and Picozzi, 2002; Llop et al., 2012). These biotic associations have been widely discussed in the literature (e.g. Simberloff and Dayan, 1991, for a review of the "functional group" concept); Tilman (2001) defining them as "a set of species that have similar traits and are thus likely to have similar effects on ecosystem functioning". According to Petchey et al. (2004), functional diversity can be considered one measure of biodiversity (such as species richness, functional group richness, functional attribute diversity) for quantifying resource use complementarity and thereby explaining and predicting ecosystem functioning. Functional groups have been widely used in ecological studies, including in an urban context (e.g. Sattler et al., 2010: insects; Bogosian et al., 2012: amphibians, reptiles, mammals; French and Picozzi, 2002; Fraterrigo and Wiens, 2005; Kark et al., 2007: birds). Contrary to the prevailing notion that bird abundance usually increases in cities, studies reporting increases or decreases of bird abundances are, in fact, about equal. The mechanisms underlying patterns of urban biodiversity are complex and not well understood yet (Faeth et al., 2012).

Few studies have been carried out on the urbanization effects on bird functional groups in large cities (Ortega-Alvarez et al., 2009: Mexico City; Strohbach et al., 2009: Leipzig), particularly in old ones. Our research is thus one of the few contributions carried out in a millenary city, which, after an $1800 \mathrm{yr}$ period of remaining more or less the same size, suddenly after 1870 underwent a progressive and circular expansion, leading to old villas and relict natural areas being incorporated into the urban fabric.

In this paper, we have focused on the possible effects of the urbanization gradient, effects of land use and the distribution of green areas in a dense urban area on avifauna community parameters and traits (habitat, nesting and feeding functional groups). We predicted that (a) bird communities (i.e. species richness, evenness) are, in general, negatively affected by urban development (land-cover transformation and urbaniza- tion gradient); (b) bird species respond to urbanization and changes in land use cover in different ways depending on their habits and requirements; in other words, different functional groups may take advantage of increasing urbanization or in other cases be harmed by it (urban adapters vs. urban avoiders; Blair, 1996); and (c) the distribution of old villas in the inner rings along the urbanization gradient likely produces disruption in the trends predicted in (a) and (b).

\section{Methods}

\subsection{Study area}

The area under consideration in the present study is the portion (36000 ha) of the Municipality of Rome (Central Italy, approximately: $41^{\circ} \mathrm{N}, 12^{\circ} \mathrm{E}$ ) encircled by the GRA ring road ("Grande Raccordo Anulare"), made up of $165 \mathrm{~km}^{2}$ of builtup areas and $175 \mathrm{~km}^{2}$ of green areas (urban gardens, archaeological zones, protected natural areas, ancient historical villas, lawns, cultivated zones, pastures for sheep and cows). Typically, in the city outskirts, green areas are characterised by residual wooded patches surrounded by pastureland and various mostly non-intensive cultures (Blasi et al., 2001; Sorace, 2001). Conversely, in the city centre, the green areas with forested land use (almost all coinciding with the old villas) host very reduced open-land habitats sited at the borders of larger expanses of wood (Sorace, 2001). The old villas date as far back as 15-16th century and show a very high number of spontaneous plant species and high habitat heterogeneity and environmental quality due to the presence of remnant woods, meadows, ponds, springs and fountains $(\mathrm{Ce}-$ lesti Grapow, 1995; Blasi et al., 2001). The same villas also represent "hot spots of biodiversity" in the city centre ( $\mathrm{Ri}$ cotta et al., 2001). In a typical old villa, $46.4 \%$ of the area consists of meadows, $37.9 \%$ of woods and $15.7 \%$ of bushes or meadows with scattered trees. Public access is unlimited during daytime and the land management is limited to grass cutting (Sorace, 2001).

In the study area, we identified all the green areas using a geographic information system (GIS). We considered as green areas all those constituting polygons (see Vignoli et al., 2009 for green areas distribution and characterization), which represent isolated patches in the mosaic landscape of Rome and comprising the following CORINE (Coordination of Information on the Environment - European Environment Agency; http://www.eea.europa.eu/publications/ COR0-landcover) land-cover categories (land use map of Municipality of Rome; scale 1:10000; 4th CORINE level; Blasi et al., unpublished data derived from land use map 1 : 50 000; Blasi et al., 2001): (a) 1.4.1. green urban areas, areas with vegetation within the urban fabric, including parks, cemeteries with vegetation and mansions and their grounds; (b) 2.4. heterogeneous agricultural areas; (c) 3. woods and semi-natural areas; and (d) 4. wetlands. In the study area, CORINE land-cover category 3 includes different wood 

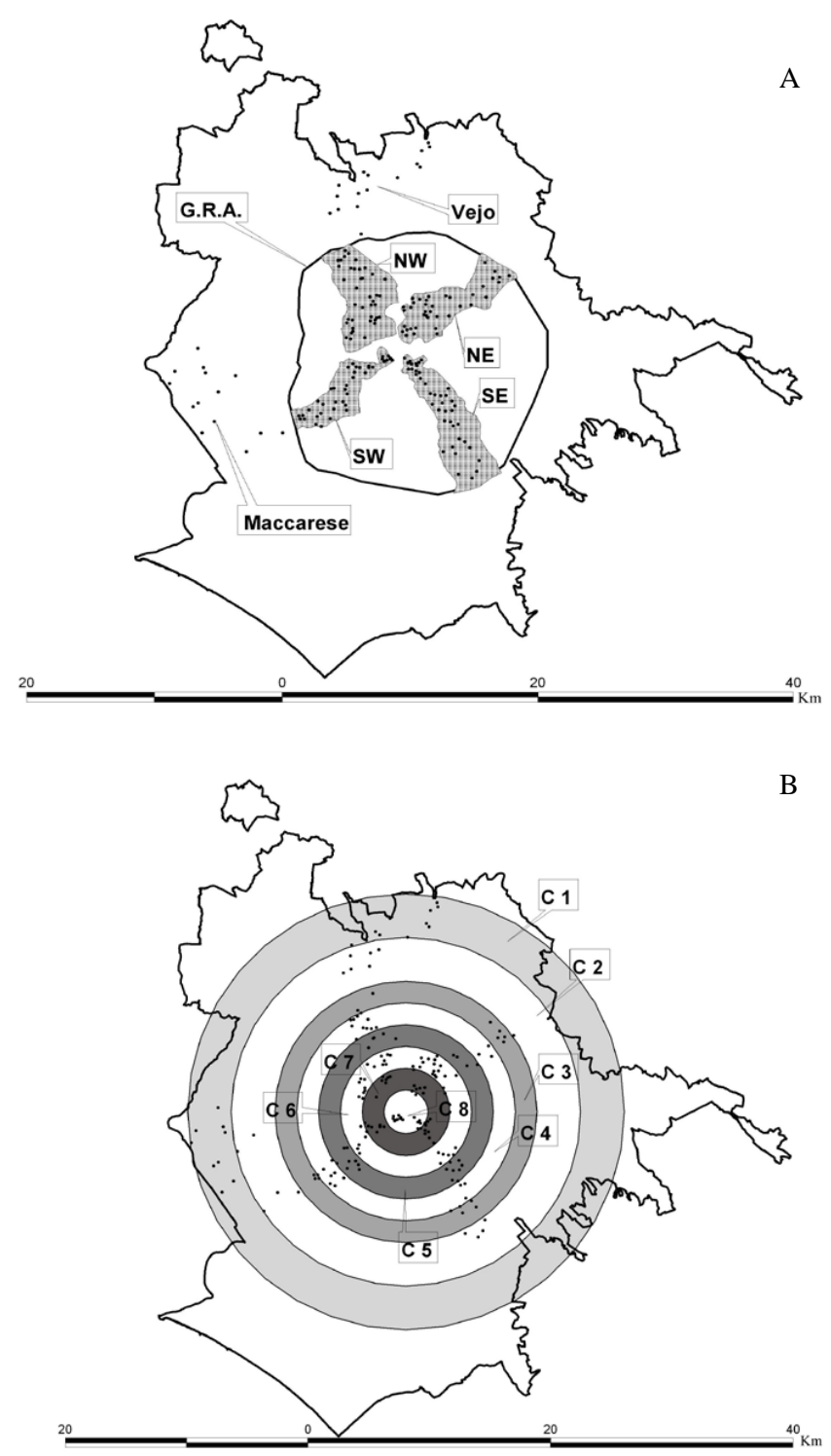

Figure 1. GIS-built maps of the study area showing (A) Municipality of Rome's borders, G.R.A. ring road, point counts' (black dots) distribution into four sectors (grey shading), and (B) eight urbanization gradient rings (UGRs; C8-C1, urban to rural gradient).

typologies (e.g. oak, pine and chestnut forests, Mediterranean maquis).

In the study area, we selected four wedge-shaped sample plots (sectors) placed along the cardinal points (NW, NE, SE, $\mathrm{SW}$ ), delimited by main roads and tapered towards the citycentre (Fig. 1a) (Vignoli et al., 2009). This procedure allowed us to investigate the whole range of urbanization levels in the town through representative samples. Each sector extends linearly from the surrounding countryside to the city centre, comprising remnant natural and semi-natural areas and eight protected areas. Two further external rural zones were considered outside the GRA's borders, these serving as compar- ison sites for gradient analysis. These are represented by the Vejo site, northwest of Rome (in the Regional Natural Park of Vejo) and the Maccarese site, southwest of the city (in the Natural State Reserve of Litorale Romano). Within each sector and the two external zones, we identified all the remnant green-space areas (Fig. 1).

\subsection{Urbanization gradient rings}

Eight concentric rings (UGRs), covering the entire surveyed area, were defined a priori (Fig. 1b). Six rings spaced at about $1.8 \mathrm{~km}$ (mean distance from city centre to GRA' borders) were included inside the GRA territory; two further rings, covering external rural zones, were spaced at $3.6 \mathrm{~km}$, taking into consideration the more diffuse development that occurs in the peripheral areas. The increased distance value for the outer rings is due to the distribution of point counts on a wider area relative to the Vejo and Maccarese sites. As regards to the distribution of historical green areas (old villas; $N=12$ ) in the city, they are present only in the three inner rings (UGRs 6-8) and in three out of four sectors (NE, SE and $\mathrm{SO})$.

\subsection{Land use categories}

Each point count station of the bird survey was assigned to one or several land use categories (LUCs), these being defined by taking into account (i) type, (ii) amount (percentage) and (iii) prevailing land use categories inside a $200 \mathrm{~m}$ circular buffer surrounding the point (Taffon and Battisti, 2006). The point count stations were chosen by a random stratified sampling approach (i.e. to achieve a minimum of five stations per land use category) within the entire study area (Table 1). Nonetheless, for some land use categories, such as Mediterranean scrub, canebrake, quarries, urban forests (non-native deciduous trees, with dominance of the alien species Robinia pseudoacacia), we were not able to pass the threshold (i.e. $n<5)$. The considered land use categories can be classified as follows: habitat mosaics (UM - urban mosaics, NM natural mosaics, AM - agricultural mosaics), forests (F woodlands), pastures (P), cultivations (UC - urbanized cultivations, $\mathrm{NC}$ - natural cultivations), urban matrix (U) and artificial green areas (AG). On the whole, the considered $(n>5)$ LUCs were represented by 176 point counts and were grouped into the three categories, namely urbanized, agricultural and natural, based on the CORINE codes (Table 1).

\subsection{Sampling methods}

Communities were studied applying the E.F.P. method (Echantillonage Frequential Progressif - Bibby and Burgess, 1992 ) in point counts at a fixed radius of $150 \mathrm{~m}$, for a total of 191 point counts, located at least $300 \mathrm{~m}$ from each other in order to decrease the possibility of double counting. Each point count station was placed entirely within a green area. Hence, 
Table 1. Synoptic table summarizing the land use categories selected in the study area. To each land use category belonging to a main land use typology a code is assigned and a concise description is provided. The number of total point count station $(N)$ falling into each land use category is also given.

\begin{tabular}{|c|c|c|c|}
\hline \multicolumn{4}{|c|}{ Land use categories } \\
\hline $\begin{array}{l}\text { Land use } \\
\text { typology }\end{array}$ & Code & Description & $N$ \\
\hline \multirow{7}{*}{ Urbanized } & UM & $\begin{array}{l}\text { urban matrix and/or artificial green areas covering less than } 50 \% \text { in surface } \\
\text { with no other land use categories covering more than } 50 \% \text { in surface }\end{array}$ & 8 \\
\hline & UC50 & $\begin{array}{l}\text { agricultural areas with significant presence of urban matrix covering between } \\
50 \text { and } 75 \% \text { of landscape surface }\end{array}$ & 10 \\
\hline & UC75 & $\begin{array}{l}\text { agricultural areas with significant presence of urban matrix covering more than } \\
75 \% \text { of landscape surface }\end{array}$ & 14 \\
\hline & U50 & urban matrix covering between 50 and $75 \%$ of landscape surface & 17 \\
\hline & U75 & urban matrix covering more than $75 \%$ of landscape surface & 6 \\
\hline & AG50 & artificial green areas covering between 50 and $75 \%$ of landscape surface & 9 \\
\hline & AG75 & artificial green areas covering more than $75 \%$ of landscape surface & 38 \\
\hline \multirow{3}{*}{ Agricultural } & $\mathrm{AM}$ & $\begin{array}{l}\text { agricultural areas covering less than } 50 \% \text { in surface with no other land use categories } \\
\text { covering more than } 50 \% \text { in surface }\end{array}$ & 16 \\
\hline & NC50 & agricultural areas covering between 50 and $75 \%$ of landscape surface absence of urban matrix & 15 \\
\hline & NC75 & agricultural areas covering more than $75 \%$ of landscape surface absence of urban matrix & 18 \\
\hline \multirow{3}{*}{ Natural } & $F>50$ & woodlands covering between 50 and $75 \%$ of landscape surface & 16 \\
\hline & NM & $\begin{array}{l}\text { forests, natural pastures or shrublands covering less than } 50 \% \text { in surface with no other land } \\
\text { use categories covering more than } 50 \% \text { in surface }\end{array}$ & 11 \\
\hline & $P>50$ & natural pastures and grasslands covering between 50 and $75 \%$ of landscape surface & 6 \\
\hline
\end{tabular}

no obstacle (buildings or anthropogenic structure) could affect (visually and/or acoustically) sampling accuracy and effectiveness. All the point count stations used in the different analyses are included within the 191 as well as the ones excluded from LUC-analyses. The point count stations of the bird survey were located (from outskirts to the city centre) in the UGRs as follows, their number being proportional to the heterogeneity of land-cover use in each UGR: UGR $1 N=18$, UGR2 $N=16$, UGR3 $N=15$, UGR4 $N=25$, UGR5 $N=25$, UGR6 $N=45$, UGR7 $N=31$ and UGR $8 N=16$. The sampling effort (number of point counts per ring) is linked to the land use categories' distribution among rings. The point count stations were localised by a random stratified criterion and the differences in the number of point count stations among rings reflect the effective land use diversity of each ring.

A modified version of E.F.P. was applied (Fuller and Langslow, 1984; Bibby and Burgess, 1992; Sorace et al., 2000), reduced to $5^{\prime}$ for point count from the original 10' and repeated twice during the breeding season in 2005 (early period: March-April; late period: May-June) (Garaffa et al., 2009; Gagné and Fahrig, 2011). In order to optimise our data set we surveyed early and late breeders and also species with different phenology (migrant and resident species). This approach is frequently suggested for temperate zones (Fuller and Langslow, 1984; Bibby and Burgess, 1992) and its results are particularly suitable for covering wide and hetero- geneous areas in a short time. Indeed, each green-area was sampled at least twice (i.e. the green-areas whose size was not large enough to include two points stations without overlapping) and up to 34 times in the case of the largest one (17 point stations each sampled twice). To minimise possible inefficiencies and biases associated with point count methods (e.g. incomplete counts, biased estimate of the relative occurrence of contacted birds) (Burnham, 1981; Barker and Sauer, 1995), we recorded only species' occurrence (presence) at each point count session. We chose to use point counts rather than estimating detection probabilities by using distance sampling (Buckland et al., 2001) for the reasons raised by Buckland et al. (2001) and Johnson (2008) and according to Gagné and Fahrig (2011): (i) in a multi-species study most species are not detected frequently enough to gather a reliable estimate of their detectability function; (ii) distance estimation has been found to be highly inaccurate (Alldredege et al., 2007); and (iii) distance sampling estimates the probability that an individual is detected by an observer (pd), this probability varies in relation to survey specific factors. In order to take variation into account in pd, separate detectability functions would have to be estimated for each the factor influencing pd, which was not feasible (Gagné and Fahrig, 2011). All bird surveys were conducted on sunny days, without strong wind or rain, from 06:00 to 11:00 LT, to coincide with peak singing activity. In our study, we excluded aquatic and nocturnal species and considered breeding species only, 
here defined as (a) potential breeder: a bird observed during its breeding season in a potentially adequate habitat, with no other indication of reproduction; (b) probable breeder: a bird observed in singing activity, territory defence or courtship; and (c) confirmed breeder: adult birds observed during transport of food, faecal refuse or nest building material, recovery of nest with eggs and/or clutches or an empty nest.

Species were classified in functional groups (Clergeau et al., 2006a) based on their nesting, habitat and foraging requirements (Wiens, 1997). Bird species were categorised into (a) five nesting functional groups according to their nest typology and nesting behaviour, (b) five habitat functional groups identified considering the land-cover typologies which birds are strictly related to (functional group A, linked to open habitats, was subdivided into three more specific subgroups) and (c) five feeding functional groups defined according to the species diet requirements. Data on species traits were obtained from Cramp (1998).

\subsection{Study scales}

In complex biotic organizations such as urban areas it is necessary to define different hierarchical levels of ecological functioning so as to avoid confusing the different mechanisms that operate at different spatial scales (Clergeau et al., 2006b). They can be defined as follows: (i) the local (or habitat) scale, which is defined by elements such as green area vegetation composition and structure or the closeness to buildings and other artificial surfaces; and (ii) the landscape level, such as districts that can differ structurally between the centre and the edge of a town for the level of urbanization and the green area availability (Clergeau et al., 2006b). We investigated our study system according to two different spatial scales. At the local scale (e.g. single point count station), we analysed the species richness as a function of three main variables: (a) distance from the city centre, (b) land use category, (c) location in or out old villas. Moreover, as the distribution of the green areas in the study system produces a mosaic of different items, which differ in terms of structure (e.g. size, shape, dominant land use type) and function (management and position within the urban texture), we tested the effect of the interactions between these three main factors on community parameters. At this scale we do not estimate evenness or dominant species because at each point count we recorded species occurrence only and not abundance.

At the landscape scale (i.e. urbanization rings - UGRs), we analysed some avian community parameters measured by pooling all the point count stations within a single UGR in terms of their relationships with (a) the urbanization gradient, (b) land use (natural, rural and urban) and management standards (old villas vs. others) and (c) the distribution and abundance of functional groups. As for the local scale, the interactions between the categorical and the continuous predictors are also evaluated to better understand the observed patterns of community parameter trends.
Table 2. Factor loadings of land use variables for the first two Factors derived from principal component analysis. In bold the land use categories significantly associated to each PCA factor.

\begin{tabular}{lrr}
\hline Land use variables & PCA 1 & PCA 2 \\
\hline Urbanized & $\mathbf{- 0 . 7 8 6}$ & 0.559 \\
Agricultural & $\mathbf{0 . 9 1 8}$ & 0.247 \\
Natural (Forested) & -0.048 & $-\mathbf{0 . 9 9 8}$ \\
Distance to urban core & $\mathbf{0 . 7 5 7}$ & -0.071 \\
Eigenvalue & 2.038 & 1.376 \\
Explained variance & 0.509 & 0.344 \\
\hline
\end{tabular}

\subsection{Data analysis}

Data from point counts were grouped as follows: eight urbanization gradient rings - UGRs (191 point counts) and 13 land use categories (176 point counts). At the landscape scale (UGRs), adequate data performance was tested by building accumulation curves (one for each UGR) to avoid nonrepresentative comparisons due to a non-exhaustive point count sampling. Due to the number of point counts (range 1-16), we could not build accumulation curves for single green area. To assess a valid data set each curve must reach a plateau.

As far as community parameters are concerned, at the local scale (point station) we assessed species richness $(S)$ as the number of checked species inside $5^{\prime}$ survey time (We considered the maximum value pooling the two survey periods; Gagné and Fahrig, 2011) and for each green area the following parameters were assessed: species richness $(S)$ (we considered the maximum value pooling all the point count stations within a given green area), relative frequency of each species among point count stations within a given green area $\left(p_{i}\right)$, evenness $(J)\left(J=H^{\prime} / H_{\max }^{\prime}\right.$ (Lloyd and Ghelardi, 1964) where $H^{\prime}=-p_{i} \sum \ln \cdot p_{i}$ and $H_{\max }^{\prime}=\ln S$ ), this index varies between 0 and 1 and focuses on an equilibrium in the distribution of species' abundance in a community and number of dominant species $(N d)$, i.e. species with frequency $>0.05$. As regards to landscape scale (UGR), community parameters were estimated by pooling all the point count stations at that scale.

In order to assess and quantify the urban-rural gradient, we performed a principal component analysis (PCA) using the dominant land-cover category (Urban, Rural. Natural; Table 2) data from each point count station and their distance from the city centre (Garaffa et al., 2009; Du Toit and Cilliers, 2011). We then used the first two factors resulting from the PCA to correlate the gradient with the community parameters. We performed the PCA based on a correlation matrix and only retained factors with associated eigenvalues greater than one (Du Toit and Cilliers, 2011). We considered as significantly correlated to a factor the variables with loading above 0.71 (Tabachnick and Fidell, 2001). In order to analyse the relationships between community parameters (i.e. 
species richness, evenness, dominant species frequency and absolute abundance of functional groups) we built different general linear models. For the various models we built, all the estimated community parameters were normally distributed and were considered as dependent variables. We built one analysis of co-variance model (GLM) to test the linear effects of two fixed factors (PCA1 and PCA2 factor sores), one random factor (sectors) and the interactions between the fixed and random factors on the number of bird species $(S)$ recorded at each point count station. Another GLM was performed to test the effects of two fixed factors (distance from the city centre and land use category), one random factor (sector) and the interactions between fixed and random factors on the number of bird species $(S)$ recorded at each point count station. All these models were performed by using all the point count stations and then repeated without considering the green areas belonging to the old villas. Another GLM was built to test the effects of one fixed factor (distance from the city centre), one random factor (functional group type) and the interaction between them on the absolute abundance of the studied functional groups. In this model the predictor "distance" represents eight increasing values estimated as the average distances from the city centre of each urbanization ring (UGR). In order to compare the bird communities of the old villas with those of the remaining green areas, we estimated the community parameters of each green area considered. As these data did not follow a normal distribution, we performed generalised linear models (GLZs) to test the difference in community parameters (dependent variables) between green area types (old villas vs. the remaining green areas, fixed categorical predictors) belonging to the same UGR (fixed categorical predictor). We built three models (one for each community parameter) testing for the linear effect of green area type, gradient (measured by UGRs) and the interaction between these two terms on the community parameters (link function: identity; error distribution: normal). With regards to functional groups, due to an uneven sampling effort, we analysed their absolute abundance estimated after rarefaction procedures by using a null model approach. Null model regressions were used to test the community parameters estimated at the landscape scale (e.g. UGRs) against the urbanization gradient represented by the PCA1 factors. This analysis gives the probability test in which the observed product-moment correlation coefficient $r$ is compared to the average $r$ obtained in simulated communities by means of 1000 randomizations. The randomization reshuffles the $y$ values only, which is sufficient to scramble the pattern with respect to the $x$ values (Gotelli and Entsminger, 2001). A multivariate analysis of variance (MANOVA) was applied to test for differences in community parameters among LUCs. Parametric tests were only used when assumptions of normality were met; when such assumptions were not met, we performed non-parametric tests (e.g. GLZ) or tests based on null model analyses (e.g. regression), which do not require any data distribution assumptions. All the statistical analyses were performed by Statistica (Statsoft, 2008; version 8.0) except for the rarefaction null model analyses, which were performed using Ecosim (version 7.72; http://garyentsminger. com/ecosim/index.htm), with two tails and alpha set at $5 \%$.

\section{Results}

The environmental changes caused by different LUCs that occurred from the city centre to the periphery were explained by rural and urban land use categories. The first PCA factor was highly and negatively correlated with urbanized coverage and positively with rural coverage (Table 2). The first PCA factor was also highly and negatively associated with the distance from the urban core. These results indicate that the considered PCA factor represented primarily a gradient of increasing rural and decreasing urbanized coverage from the urban core to the periphery. The second PCA factor was significantly linked to natural land use categories but not to the distance from the city centre.

\subsection{Local scale}

Considering all 191 point counts carried out, a total of 90 bird species were surveyed during the study, 69 of them being considered as breeding in Rome (potential, probable and confirmed breeders). For the analyses, 64 species were considered, after exclusion of those sighted flying over the sampling station due to their uncertain link to the sampling site (Table 3) and 176 point counts belonging to those land use categories with $n>5$. The species richness at this study scale was clearly influenced by the rural-urban gradient. The relationships between species richness and the study gradient was unimodal (humpbacked); the curve that best fitted the data distribution was a second order polynomial (difference in AICc with a linear model $=8.946, R=-0.365, p<0.001$. Non-linear PCA regression was performed by using PCA1 factor scores against number of species (Fig. 2). The species richness showed a quadratic relationship with the PCA2 factor (curve not shown) but with an inverse pattern (i.e. concave) in respect to PCA1 (difference in AICc with a linear model $=7.558, R=0.07, p=0.002$ ).

The GLM analyses performed on species richness data (PCA factors scores as fixed predictors and sectors as random predictors) revealed a significant influence of the study gradient (PCA1) and a marginally significant effect of natural land use categories (PCA2) in interaction with sector (Table 4). When the point counts belonging to the old villas were excluded from the analysis, the GLM showed the same pattern with the addition of a positive significant effect of PCA2 as a single effect (Table 4). In the analysis of covariance (fixed factor: LUC, random factor: sector, covariate: distance) including all the point counts and all the land use categories (urban, rural and natural), the number of bird species recorded at each point count station was not influenced by any of the effects tested (Table 5). At this study scale (point 


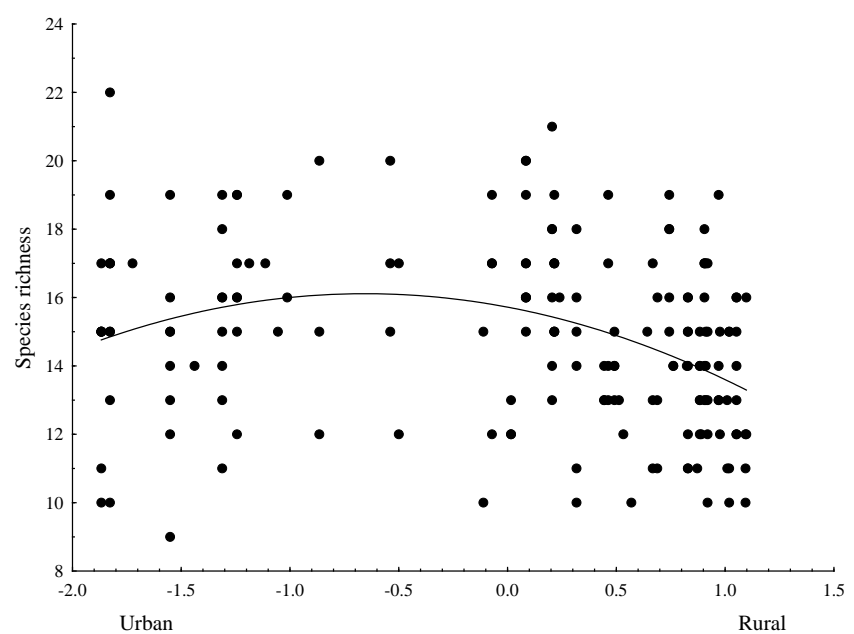

Figure 2. Non-linear principal component analysis regression showing the relationship between bird species richness (recorded at each point count station) and rural-urban gradient associated to the Factor 1 obtained from PCA. Best function fitting data distribution: $y=15.600-0.821 \cdot x-0.463 \cdot x^{2} . R=-0.370 ; N=182 ; p<0.001$.

count station), the land use typology (LUC) had no effect on species richness either when analysed as single factor or in interaction with distance and sector. When the same analysis was performed, excluding the data belonging to the old villas, the species richness was significantly affected by the interaction between LUC and the distance from the city centre (Table 5). Hence, the exclusion of point counts representing mainly human modified land uses (old villas) and sited in the inner portion of the city, revealed a negative effect of the urbanization gradient comprising all the land use categories on the species richness. In other words, the old villas mitigate the effect of urbanization in the inner portion of the city by reducing the gap between natural and human modified land uses as far as the number of bird species is concerned.

\subsection{Landscape scale}

\subsubsection{Urbanization gradient rings (UGRs)}

In the inner rings the green areas are higher in number but smaller in surface than those in the outer rings and consequently they present a smaller number of point count stations per green area (Table 4). The accumulation curves (the number of new recorded species against the sampling effort - number of point counts) performed for UGRs stabilised after reaching a plateau (see Appendix Fig. A1). Despite a different sampling effort among UGRs, nearly all the accumulation curves reached the plateau value when truncated at the minimum number of samples $(N=15)$ shared by all the rings.

Inside the eight concentric rings, all 64 study species were checked. Three species were dominant $(\mathrm{Fr}>0.05)$ inside all rings: Turdus merula, Sylvia atricapilla and Corvus corone.
Species richness decreased with increasing urbanization. If the old villas are removed from the bird community analysis, the species richness decrease showed a much higher significant trend (Table 6). Evenness showed a significant negative trend from periphery to city centre, whereas for the number of dominant species the opposite trend was found (Table 6). The comparison of community parameters between the bird assemblages from the old villas and those from the other fragments showed no significant differences $(S$ : Wald $_{1}=1.926, p=0.165, J$ : Wald $_{1}=0.160, p=0.689$, ND: Wald $_{1}=0.106, p=0.744$, GLZ). The comparisons within rings 6,7 and 8 (i.e. those containing the old villas, $n=3,6$ and 3 , respectively) showed that in two out of the three analysed rings (the inner UGR7 - nearly significant - and UGR8) the assemblages belonging to the historical villas were, on average, richer in respect to those found in the remaining fragments of the same ring (UGR7: $n=11, \mathrm{U}=5, p=0.068$, UGR8: $n=8, \mathrm{U}=0.5, p=0.037$ ), whereas evenness and dominant species showed no significant pattern (Fig. 3).

\subsubsection{Functional groups}

By and large, all the functional groups categories were influenced by the study gradient, the various functional groups responding in different ways to the distance from the city centre (Table 7). The analysis of the nesting functional groups (see Table 3 for functional group composition) revealed that the absolute abundance of ground $(\mathrm{T})$ and artificial cavity (AC) breeders showed two contrasting trends from external to internal UGRs along the ruralurban gradient (T: $r_{\mathrm{obs}}=-0.960, p=0$, AC: $r_{\mathrm{obs}}=0.805$, $p=0.009$ ). The abundance of ground nesting species exhibited a significant negative trend from periphery to city centre, whereas the opposite was true for the species exploiting artificial cavities (Fig. 4a). The analysis of the habitat functional groups showed that species linked to open habitats sensu lato (Functional group A), which include cereal cultivations, semi-natural pastures and bushy meadows, underwent a clear reduction in numbers from external to internal UGRs $\left(r_{\mathrm{obs}} r=-0.970 ; p=0\right.$; Fig. 4b). The three open habitat sub-functional groups responded in the same way, the exception being the open Mediterranean shrubby habitat, which showed no significant relationship with the urbanization gradient (AE: $r_{\mathrm{obs}}=-0.966, p=0, \mathrm{AE} 2: r_{\mathrm{obs}}=-0.488$, $\left.p=0.115, \mathrm{AS}+\mathrm{AN}: r_{\mathrm{obs}}=-0.920, p=0.003\right)$. Functional groups connected to forested habitats exhibited two opposite trends. Species linked to open forest habitats (FA) showed a significant reduction from periphery to city centre $\left(r_{\mathrm{obs}}=\right.$ $0.663, p=0.033$ ), whereas those associated with denser forest habitats $(F)$ increased the closer they were to the city centre $\left(r_{\text {obs }}=0.852, p=0.006\right)$ (Fig. $\left.4 \mathrm{~b}\right)$. Both the trends observed for the forest and open forest functional groups presented a discontinuity in the curve slope in the middle of the urbanization gradient (UGR4) (Fig. 4b). Species linked to the urban matrix revealed a nearly significant trend similar 
Table 3. Complete list and relative frequency of the observed breeding species in the study area grouped by habitat and nesting site functional groups. Dominant species (i.e. with relative frequency $>0.05$ ) are in bold. Abbreviations: SW, SE, NE, NW: sector codes referring to their cardinal position. n.f.: species not found inside sectors, but inside two selected external areas; ${ }^{1}=$ species flying over the station, not strictly breeding in the study area and not considered in the analyses; ${ }^{2}=$ alien species. Habitat functional groups: $\mathrm{A}=$ open habitats (from cultivations to arboreal shrublands); FA = open forested habitats (mixture of wooded areas and open habitats); $F=$ forested habitats with prevalence of woodlands; $\mathrm{U}=$ urban habitats, with prevalence of urban matrix; $\mathrm{MX}=$ mixed categories (A, $\mathrm{U}$ and $\mathrm{UV}$ ); n.c. = species not strictly related to the used habitat categories. Functional group A was subdivided into four further subgroups: AE = open heterogeneous environments; AE2 = open environments, xeric, usually represented by Mediterranean scrubs assessments; AS = cultivations, AN = open natural environments with prevalence of grasslands, without trees or shrubs. Nesting site functional groups: $\mathrm{AC}=$ tree cavities; $\mathrm{AR}=$ shrubs, bushes; $\mathrm{AV}=\mathrm{open}$ trees; $\mathrm{CP}=$ artificial anthropic cavities; $\mathrm{T}$ = ground; feeding functional groups: $\mathrm{FR}=$ frugivorous; $\mathrm{G}=$ granivorous; $\mathrm{H}=$ herbivorous; $\mathrm{I}=$ insectivorous; $\mathrm{O}=$ omnivorous; $\mathrm{P}=$ predators (species feeding at least in part on vertebrates).

\begin{tabular}{|c|c|c|c|c|c|c|c|c|}
\hline \multirow[t]{3}{*}{ BREEDING SPECIES } & \multicolumn{4}{|c|}{ FUNCTIONAL GROUPS } & \multicolumn{4}{|c|}{ RELATIVE FREQUENCIES } \\
\hline & \multirow[b]{2}{*}{ (a) } & \multirow{2}{*}{$\begin{array}{l}\text { Habitat } \\
\text { (b) }\end{array}$} & \multirow[t]{2}{*}{ Nesting } & \multirow[t]{2}{*}{ Feeding } & \multicolumn{4}{|c|}{ Sectors } \\
\hline & & & & & SW & SE & NE & NW \\
\hline Anas platyrhynchos & n.c. & & n.c. & $\mathrm{H}$ & 0.005 & & 0.002 & \\
\hline Milvus migrans & FA & & AV & $\mathrm{P}$ & 0.002 & & & \\
\hline Accipiter nisus & $\mathrm{F}$ & & $\mathrm{AV}$ & $\mathrm{P}$ & & & & \\
\hline Buteo buteo & FA & & AV & $\mathrm{P}$ & & 0.002 & & \\
\hline Falco tinnunculus & A & $\mathrm{AE}$ & $\mathrm{CP}$ & $\mathrm{P}$ & & 0.010 & 0.007 & 0.008 \\
\hline Coturnix coturnix & A & $\mathrm{AS}, \mathrm{AN}$ & $\mathrm{T}$ & $\mathrm{G}$ & & 0.005 & 0.004 & \\
\hline Phasianus colchicus & n.c. & & $\mathrm{T}$ & G & 0.021 & 0.012 & 0.004 & 0.003 \\
\hline Gallinula chloropus & n.c. & & n.c. & $\mathrm{O}$ & 0.004 & & 0.002 & \\
\hline Larus michahellis $^{1}$ & n.c. & & n.c. & & & & & \\
\hline Columbia livia & $\mathrm{U}$ & & $\mathrm{CP}$ & G & 0.025 & 0.042 & 0.039 & 0.012 \\
\hline Streptopelia decaocto & $\mathrm{U}$ & & n.c. & G & 0.021 & 0.024 & 0.006 & 0.003 \\
\hline Streptopelia turtur ${ }^{2}$ & FA & & AV & $\mathrm{G}$ & 0.016 & 0.003 & 0.002 & 0.013 \\
\hline Psittacula krameri ${ }^{2}$ & n.c. & & $\mathrm{AC}$ & $\mathrm{F}$ & 0.016 & 0.019 & 0.006 & \\
\hline Myiopsitta monachus & n.c. & & AV & $\mathrm{F}$ & 0.002 & 0.014 & & \\
\hline Cuculus canorus & $\mathrm{F}$ & & $\mathrm{AV}$ & I & 0.002 & & 0.002 & \\
\hline Strix aluco & $\mathrm{F}$ & & $\mathrm{AC}$ & $\mathrm{P}$ & & & 0.002 & \\
\hline Apus apus ${ }^{1}$ & n.c. & & n.c. & I & & & & \\
\hline Alcedo atthis & n.c. & & n.c. & $\mathrm{P}$ & & 0.002 & & \\
\hline Merops apiaster & A & $\mathrm{AE}$ & n.c. & I & 0.005 & 0.005 & 0.002 & 0.017 \\
\hline Upupa ерорs & FA & & $\mathrm{AC}$ & I & & 0.003 & 0.002 & \\
\hline Jynx torquilla & FA & & $\mathrm{AC}$ & I & 0.005 & 0.012 & 0.009 & 0.018 \\
\hline Picus viridis & FA & & $\mathrm{AC}$ & I & 0.005 & & 0.006 & 0.017 \\
\hline Dendrocopos major & $\mathrm{F}$ & & $\mathrm{AC}$ & I & 0.007 & 0.003 & 0.007 & 0.015 \\
\hline Calandrella brachydactyla & n.c. & & $\mathrm{T}$ & G & & & & \\
\hline Galerida cristata & A & AS,AN & $\mathrm{T}$ & G & 0.004 & 0.015 & 0.006 & 0.002 \\
\hline Alauda arvensis & A & $\mathrm{AS}, \mathrm{AN}$ & $\mathrm{T}$ & G & 0.012 & 0.008 & 0.004 & \\
\hline Hirundo rustica ${ }^{1}$ & n.c. & & n.c. & I & & & & \\
\hline Delichon urbicum ${ }^{1}$ & n.c. & & n.c. & I & & & & \\
\hline Motacilla alba & $\mathrm{U}$ & & $\mathrm{CP}$ & I & 0.007 & 0.007 & 0.009 & 0.003 \\
\hline Motacilla cinerea $^{1}$ & n.c. & & n.c. & I & & & & \\
\hline Troglodytes troglodytes & $\mathrm{F}$ & & $\mathrm{AR}$ & $\mathbf{I}$ & 0.058 & 0.056 & 0.066 & 0.063 \\
\hline Erithacus rubecula & $\mathrm{F}$ & & $\mathrm{AR}$ & I & 0.037 & 0.029 & 0.030 & 0.032 \\
\hline Luscinia megarhynchos & A & $\mathrm{AE}$ & $\mathrm{AR}$ & I & 0.033 & 0.029 & 0.009 & 0.048 \\
\hline Saxicola rubicola & A & $\mathrm{AE}$ & n.c. & I & 0.004 & 0.005 & 0.004 & 0.005 \\
\hline Monticola solitarius & n.c. & & $\mathrm{CP}$ & I & & 0.002 & & \\
\hline Turdus merula & $\mathrm{F}$ & & AR & $\mathbf{I}$ & 0.063 & 0.066 & 0.073 & 0.063 \\
\hline Cettia cetti & n.c. & & $\mathrm{AR}$ & I & 0.012 & 0.010 & 0.013 & 0.018 \\
\hline Cisticola juncidis & n.c. & & n.c. & I & 0.018 & 0.022 & 0.017 & 0.013 \\
\hline Acrocephalus scirpaceus & n.c. & & n.c. & I & & & 0.002 & \\
\hline Hippolais polyglotta & A & AE2 & $\mathrm{AR}$ & I & & & 0.002 & 0.002 \\
\hline Sylvia atricapilla & $\mathrm{F}$ & & AV & $\mathbf{I}$ & 0.065 & 0.063 & 0.066 & 0.066 \\
\hline Sylvia cantillans & A & AE2 & AR & I & & & & \\
\hline Sylvia communis & $\mathrm{A}$ & AE2 & $\mathrm{AR}$ & I & 0.002 & & & \\
\hline Sylvia melanocephala & $\mathrm{A}$ & AE2 & $\mathrm{AR}$ & I & 0.032 & 0.022 & 0.013 & 0.043 \\
\hline Phylloscopus collybita & $\mathrm{F}$ & & $\mathrm{AR}$ & I & & & & 0.003 \\
\hline Regulus ignicapilla & $\mathrm{F}$ & & $\mathrm{AV}$ & I & 0.019 & 0.020 & 0.041 & 0.037 \\
\hline
\end{tabular}


Table 3. Continued.

\begin{tabular}{|c|c|c|c|c|c|c|c|c|}
\hline \multirow[t]{3}{*}{ BREEDING SPECIES } & \multicolumn{4}{|c|}{ FUNCTIONAL GROUPS } & \multicolumn{4}{|c|}{ RELATIVE FREQUENCIES } \\
\hline & \multirow[b]{2}{*}{ (a) } & \multirow{2}{*}{$\begin{array}{l}\text { Habitat } \\
\text { (b) }\end{array}$} & \multirow[t]{2}{*}{ Nesting } & \multirow[t]{2}{*}{ Feeding } & \multicolumn{4}{|c|}{ Sectors } \\
\hline & & & & & SW & SE & $\mathrm{NE}$ & NW \\
\hline Muscicapa striata & n.c. & & $\mathrm{AR}$ & I & 0.002 & 0.002 & & 0.003 \\
\hline Aegithalos caudatus & $\mathrm{F}$ & & $\mathrm{AV}$ & & 0.005 & 0.003 & 0.007 & 0.005 \\
\hline Cyanistes caeruleus & $\mathrm{F}$ & & $\mathrm{AC}$ & I & 0.061 & 0.037 & 0.058 & 0.051 \\
\hline Parus major & $\mathrm{F}$ & & $\mathrm{AC}$ & $\mathbf{I}$ & 0.063 & 0.054 & 0.069 & 0.060 \\
\hline Sitta europaea & $\mathrm{F}$ & & $\mathrm{AC}$ & I & 0.004 & & & \\
\hline Certhia brachydactyla & $\mathrm{F}$ & & $\mathrm{AC}$ & I & 0.030 & 0.036 & 0.045 & 0.032 \\
\hline Remiz pendulinus & n.c. & & $\mathrm{AV}$ & I & 0.002 & & & \\
\hline Oriolus oriolus & FA & & $\mathrm{AV}$ & I & & & & 0.002 \\
\hline Lanius collurio & A & $\mathrm{AE}$ & $\mathrm{AR}$ & $\mathrm{P}$ & & & & 0.002 \\
\hline Lanius senator & A & $\mathrm{AE}$ & $\mathrm{AR}$ & $\mathrm{P}$ & & & & \\
\hline Garrulus glandarius & FA & & $\mathrm{AV}$ & $\mathrm{O}$ & & & & \\
\hline Pica pica & A & $\mathrm{AE}$ & $\mathrm{AV}$ & $\mathrm{O}$ & & & f. & \\
\hline Corvus corone & MX & & $\mathrm{AV}$ & $\mathbf{O}$ & 0.070 & 0.066 & 0.067 & 0.063 \\
\hline Corvus monedula & n.c. & & $\mathrm{CP}$ & $\mathrm{O}$ & 0.002 & 0.008 & & \\
\hline Sturnus vulgaris & MX & & n.c. & $\mathbf{O}$ & 0.056 & 0.064 & 0.062 & 0.056 \\
\hline Passer domesticus & $\mathrm{U}$ & & $\mathrm{AV}$ & $\mathbf{G}$ & 0.053 & 0.054 & 0.052 & 0.038 \\
\hline Passer montanus & $\mathrm{U}$ & & $\mathrm{AV}$ & G & & & & 0.002 \\
\hline Fringilla coelebs & $\mathrm{F}$ & & $\mathrm{AV}$ & $\mathrm{G}$ & 0.030 & 0.015 & 0.036 & 0.030 \\
\hline Serinus serinus & MX & & n.c. & $\mathrm{G}$ & 0.049 & 0.059 & 0.062 & 0.051 \\
\hline Carduelis carduelis & MX & & $\mathrm{AV}$ & $\mathrm{G}$ & 0.023 & 0.030 & 0.026 & 0.032 \\
\hline Carduelis chloris & MX & & $\mathrm{AV}$ & $\mathrm{G}$ & 0.047 & 0.052 & 0.058 & 0.055 \\
\hline Emberiza cirlus & A & $\mathrm{AE}$ & $\mathrm{AR}$ & $\mathrm{G}$ & 0.005 & & & 0.012 \\
\hline Miliaria calandra & $\mathrm{A}$ & $\mathrm{AE}$ & $\mathrm{T}$ & G & & 0.008 & 0.002 & 0.002 \\
\hline
\end{tabular}

Table 4. Analysis of co-variance (GLM) of the effects of two fixed factors (PCA factor sores) and one random factor (sectors) on the number of bird species $(S)$ recorded at each point count station. The models were performed by using all the point count stations (above) and then repeated without considering the green areas belonging to the old villas (below).

\begin{tabular}{lll|llll}
\hline \multicolumn{2}{c}{ Dependent variable: $S$} & \multicolumn{3}{c}{ Tests of between-subjects effects } \\
\hline Source & Effect & $\begin{array}{l}\text { Type III sum } \\
\text { of squares }\end{array}$ & df & Mean square & F & Sig. \\
& & & & & \\
\hline Intercept & Fixed & 31076.390 & 1 & 31076.0 & 5113.500 & 0 \\
PCA1 & Fixed & 65.130 & 1 & 65.13 & 10.716 & 0.001 \\
PCA2 & Fixed & 11.270 & 1 & 11.27 & 1.854 & 0.175 \\
Sector & Random & 11.817 & 3 & 3.939 & 0.644 & 0.588 \\
Sector $\times$ PCA1 & Random & 26.370 & 3 & 8.79 & 1.446 & 0.231 \\
Sector $\times$ PCA2 & Random & 66.700 & 3 & 22.23 & 3.659 & 0.014 \\
Error & & 1014.910 & 167 & 6.08 & & \\
\hline No old villas & & & & & & \\
\hline Intercept & Fixed & 27992.147 & 1 & 27992.14 & 4305.707 & 0 \\
PCA1 & Fixed & 46.969 & 1 & 46.969 & 7.225 & 0.008 \\
PCA2 & Fixed & 26.827 & 1 & 26.827 & 4.127 & 0.044 \\
Sector & Random & 11.099 & 3 & 3.700 & 0.564 & 0.640 \\
Sector $\times$ PCA1 & Random & 65.060 & 3 & 21.687 & 3.336 & 0.275 \\
Sector $\times$ PCA2 & Random & 57.715 & 3 & 19.238 & 2.932 & 0.036 \\
Error & & 907.340 & 138 & 6.570 & & \\
\hline
\end{tabular}


Table 5. GLM analyses of the effects of two fixed factors (distance and land use category - LUC) and one random factor (sector) on the number of bird species $(S)$ recorded at each point count station. The models were performed by using all the point count stations (above) and then repeated without considering the green areas belonging to the old villas (below).

\begin{tabular}{|c|c|c|c|c|c|c|}
\hline \multicolumn{3}{|c|}{ Dependent variable: $S$} & \multicolumn{4}{|c|}{ Tests of between-subjects effects } \\
\hline Source & Effect & $\begin{array}{l}\text { Type III sum } \\
\text { of squares }\end{array}$ & $\mathrm{df}$ & Mean square & $\mathrm{F}$ & Sig. \\
\hline Intercept & Fixed & 1032.971 & 1 & 1032.971 & 182.531 & 0 \\
\hline LUC & Fixed & 21.878 & 1 & 10.939 & 1.984 & 0.141 \\
\hline Distance & Fixed & 0.097 & 1 & 0.097 & 0.015 & 0.902 \\
\hline Sector & Random & 13.595 & 3 & 4.532 & 1.459 & 0.277 \\
\hline LUC $\times$ Sector & Random & 23.695 & 4 & 3.385 & 0.557 & 0.790 \\
\hline LUC $\times$ Distance & Fixed & 40.546 & 2 & 13.515 & 2.223 & 0.088 \\
\hline LUC $\times$ Distance $\times$ Sector & Random & 47.921 & 7 & 6.846 & 1.126 & 0.350 \\
\hline \multicolumn{7}{|l|}{ No old villas } \\
\hline Intercept & Fixed & 990.231 & 1 & 990.231 & 164.499 & 0 \\
\hline LUC & Fixed & 29.300 & 1 & 14.650 & 2.476 & 0.091 \\
\hline Distance & Fixed & 0.038 & 1 & 0.038 & 0.006 & 0.938 \\
\hline Sector & Random & 11.648 & 3 & 3.883 & 0.612 & 0.608 \\
\hline LUC $\times$ Sector & Random & 34.956 & 4 & 4.994 & 0.787 & 0.599 \\
\hline LUC $\times$ Distance & Fixed & 53.784 & 2 & 17.928 & 2.827 & 0.041 \\
\hline LUC $\times$ Distance $\times$ Sector & Random & 52.210 & 7 & 7.459 & 1.176 & 0.321 \\
\hline
\end{tabular}

Table 6. Distribution of green areas and structural parameters of bird communities inside eight urbanization rings and correlation with the distance to the city centre and the urbanization gradient (from periphery to centre). The distance is expressed in meters. The gradient is represented by the average PCA1 scores of all local point in a given UGR; for each community parameter the $r$ values for regression with distance (above) and gradient (below) are reported; $r_{\mathrm{obs}}=$ observed $\mathrm{r}$ in null model regression. Abbreviations: UGR $=$ urbanization ring; $N$ $\mathrm{GA}=$ number of green areas; PCS/GA = number of point count stations per green area; $S=$ species richness; $S$ (woOV) = species richness without old villas; $J=$ evenness; $N d=$ dominant species.

\begin{tabular}{|c|c|c|c|c|c|c|c|c|c|c|}
\hline \multirow[t]{2}{*}{ Parameter } & \multirow{2}{*}{\multicolumn{8}{|c|}{ Urbanization ring }} & \multicolumn{2}{|c|}{ statistics } \\
\hline & & & & & & & & & $r_{\mathrm{obs}}$ & $p$ level \\
\hline Ring & UGR1 & UGR2 & UGR3 & UGR4 & UGR5 & UGR6 & UGR7 & UGR8 & & \\
\hline$N$ GA & 2 & 2 & 6 & 6 & 8 & 14 & 11 & 8 & 0.799 & 0.014 \\
\hline PCS/GA & 9.0 & 8.0 & 2.5 & 4.2 & 3.1 & 3.2 & 2.8 & 2.0 & -0.861 & 0.005 \\
\hline Distance & 14202 & 13034 & 10053 & 8352 & 7142 & 4399 & 2915 & 1739 & & \\
\hline Gradient & 1.145 & 1.014 & 0.448 & 0.591 & 0.061 & -0.340 & -1.057 & -1.159 & & \\
\hline$S$ & 41 & 41 & 40 & 46 & 39 & 42 & 33 & 29 & $\begin{array}{l}0.633 \\
0.782\end{array}$ & $\begin{array}{l}0.052 \\
0.017\end{array}$ \\
\hline$S$ (woOV) & 41 & 41 & 40 & 46 & 39 & 38 & 28 & 22 & $\begin{array}{l}0.748 \\
0.869\end{array}$ & $\begin{array}{l}0.013 \\
0.004\end{array}$ \\
\hline$J$ & 0.92 & 0.92 & 0.91 & 0.89 & 0.91 & 0.88 & 0.87 & 0.89 & $\begin{array}{l}0.835 \\
0.762\end{array}$ & $\begin{array}{l}0.033 \\
0.025\end{array}$ \\
\hline$N d$ & 0.12 & 0.20 & 0.20 & 0.13 & 0.21 & 0.22 & 0.34 & 0.39 & $\begin{array}{l}-0.845 \\
-0.932\end{array}$ & $\begin{array}{r}0 \\
0.002\end{array}$ \\
\hline
\end{tabular}

to that observed for the forest habitat functional group $\left(r_{\mathrm{obs}}=\right.$ $0.578, p=0.073)$. Species associated with mixed categories did not show any significant trend $\left(r_{\mathrm{obs}}=0.018, p=0.461\right)$. The functional groups based on diet requirements showed contrasting correlations to the urbanization rings: omnivorous bird abundance was positively related to the increasing urbanization $\left(r_{\mathrm{obs}}=0.702, p=0.035\right)$, whereas for granivo- rous $\left(r_{\mathrm{obs}}=-0.881, p=0.001\right)$ and predator $\left(r_{\mathrm{obs}}=-0.835\right.$, $p=0.012$ ) functional groups the opposite trend was found (Fig. 4c).

\subsubsection{Land use categories (LUCs)}

Turdus merula, S. atricapilla and C. corone were dominant in 12 out of 13 selected LUCs. The considered 
Table 7. General linear model analyses of the effects of one fixed factor (distance) and one random factor (group) on the absolute abundance of the studied functional groups. The predictor "distance" represents eight increasing values estimated as the average distances from the city centre of each urbanization ring (UGR).

\begin{tabular}{|c|c|c|c|c|c|c|c|}
\hline & \multicolumn{3}{|c|}{ Dependent variable: $S$ Group } & \multicolumn{4}{|c|}{ Tests of between-subjects effects } \\
\hline & Source & Effect & $\begin{array}{l}\text { Type III sum } \\
\text { of squares }\end{array}$ & df & Mean square & $\mathrm{F}$ & Sig. \\
\hline \multirow{5}{*}{ Nesting } & Intercept & Fixed & 13014.00 & 1 & 13014.00 & 9.686 & 0.035 \\
\hline & Group & Random & 5374.26 & 4 & 1343.57 & 29.232 & \\
\hline & Distance & Fixed & 128.10 & 1 & 128.10 & 0.610 & 0.478 \\
\hline & Group $\times$ Distance & Random & 839.33 & 4 & 209.83 & 4.565 & 0.005 \\
\hline & Error & & 1378.84 & 30 & 45.96 & & \\
\hline \multirow{5}{*}{ Habitat } & Intercept & Fixed & 12113.79 & 1 & 12113.79 & 14.353 & 0.012 \\
\hline & Group & Random & 4343.74 & 5 & 868.75 & 21.860 & 0 \\
\hline & Distance & Fixed & 108.49 & 1 & 108.49 & 0.229 & 0.651 \\
\hline & Group $\times$ Distance & Random & 2360.29 & 5 & 472.06 & 11.878 & 0 \\
\hline & Error & & 1430.64 & 36 & 39.74 & & \\
\hline \multirow{5}{*}{ Trophic } & Intercept & Fixed & 21869.96 & 1 & 21869.96 & 4.973 & 0.111 \\
\hline & Group & Random & 13190.88 & 3 & 4396.96 & 50.391 & 0 \\
\hline & Distance & Fixed & 225.48 & 1 & 225.48 & 0.967 & 0.397 \\
\hline & Group $\times$ Distance & Random & 698.92 & 3 & 232.97 & 2.670 & 0.070 \\
\hline & Error & & 2094.14 & 24 & 87.26 & & \\
\hline
\end{tabular}

Table 8. Structural parameters of bird communities inside 13 selected land use categories (LUCs). See Table 1 for land use codes and groups. Community parameter abbreviations: $S=$ species richness; $J=$ Evenness; $N d=$ dominant species.

\begin{tabular}{lllll}
\hline \multicolumn{2}{c}{ LUCs } & \multicolumn{4}{l}{ Community parameters } \\
\hline Group & Single & $S$ & $J$ & Nd \\
\hline \multirow{5}{*}{ Urbanized } & MU & 31 & 0.920 & 0.357 \\
& UC50 & 36 & 0.923 & 0.265 \\
& UC75 & 42 & 0.920 & 0.179 \\
& U50 & 29 & 0.903 & 0.345 \\
& VA5 & 26 & 0.940 & 0.320 \\
Agricultural & 27 & 0.916 & 0.458 \\
& VA75 & 35 & 0.875 & 0.364 \\
\hline \multirow{4}{*}{ Natural } & MA & 47 & 0.904 & 0.190 \\
& SN75 & 48 & 0.911 & 0.163 \\
& F $>50$ & 41 & 0.906 & 0.167 \\
\hline & MN & 41 & 0.923 & 0.194 \\
\hline
\end{tabular}

community parameters differed significantly among the LUC groups "urbanized", "agricultural" and "natural" (Wilks lambda $=0.218, \mathrm{~F}_{12,6}=3.050, p<0.036$, MANOVA). Agricultural LUCs showed, on average, significantly higher number of species than urban LUCs ( $p=0.003$, Tuckey HSD post hoc test) while for $N d$ (number of dominant species) the contrary was true $(p=0.045)$ (Table 8 , Fig. 5).
When all the sampling points of a particular land use type (urbanized, agricultural and natural) within a particular UGR are aggregated and the mean distance to the centre of each point is used, the models built with LUCs (categorical predictor) and the distance (continuous predictor) confirmed the effect of the terms LUCs and distance on species richness and evenness (for all tests and effects: Wald $\geq 8.196, p \leq 0.017$, generalised linear models) but not for dominant species, which showed no effect. Moreover, the interaction term "LUCs $\times$ distance" had an effect on bird community parameters (for all tests and effects: Wald $\geq 10.078, p \leq 0.006$ ). In particular, the agricultural land use categories showed a decreased species richness $\left(B=-6.910 \times 10^{-6}\right.$, Wald $=21.628$, $p=0$ ) with increasing urbanization; the same patterns were found for evenness in natural land use categories $(B=0.001$, Wald $=9.156, p=0.002$ ) and dominant species in natural habitats increased with the proximity to the city centre $(B=$ $2.398 \times 10^{-5}$, Wald $=7.603, p=0.006$ ).

\section{Discussion}

\subsection{General considerations}

We found a negative effect of urbanization at both local and landscape scales in regards to bird community richness and evenness. Functional groups revealed contrasting patterns linked to the rural-urban gradient by responding in a group specific way to the degree of urbanization.

In our surveys we recorded a total of 69 breeding species. The only comprehensive study on the same area (five 

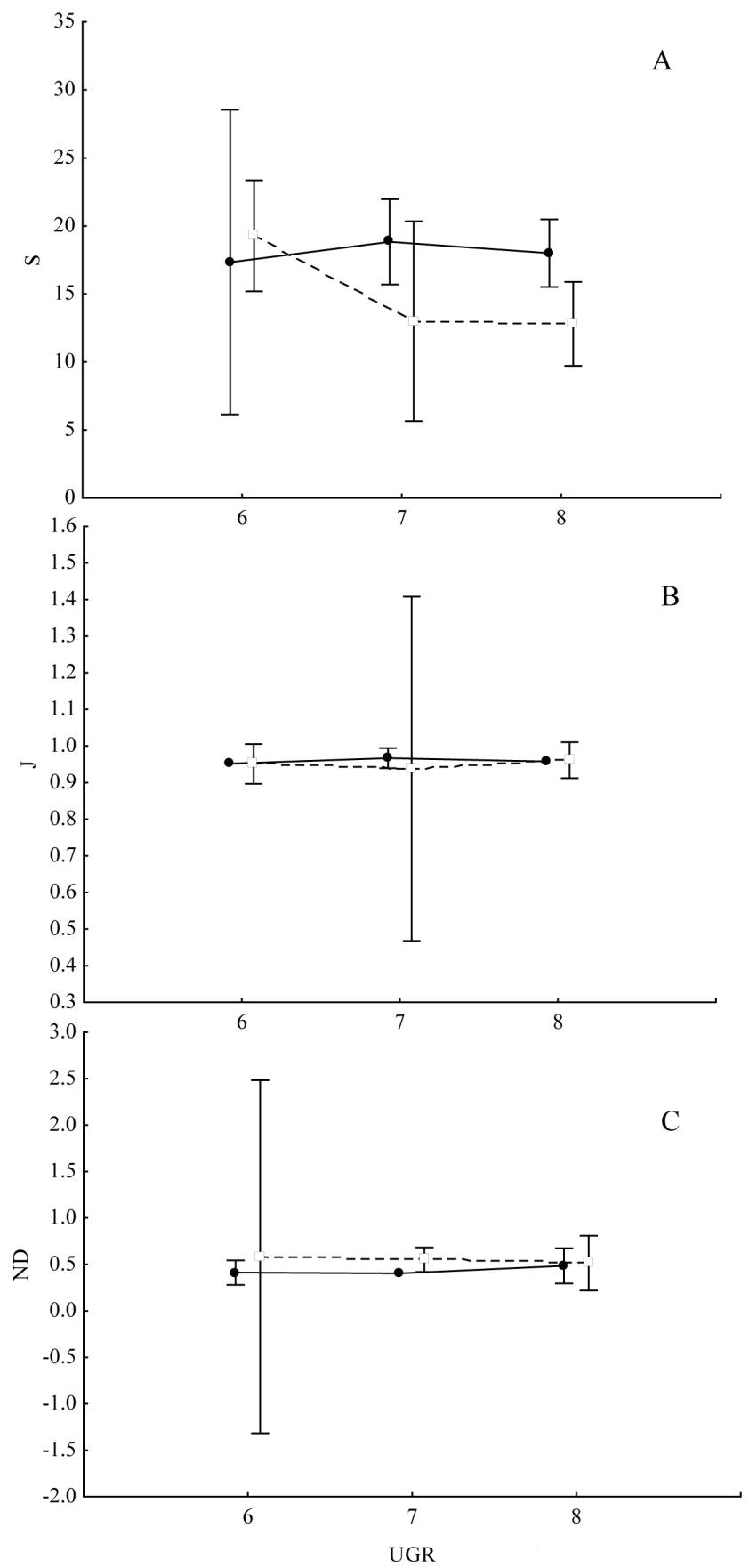

Figure 3. Bird community parameters estimated in the old villas and in the remaining green areas within UGRs 6, 7, and 8. The comparisons were performed by means of generalised linear models with the green area typology and UGR used as categorical predictors. In the plots the marginal means for the interaction effect between the predictors are shown. (A) Species richness $(S) \times$ UGR (Wald: $\left.\chi_{(2)}^{2}=10.286, p=0.006\right)$; $($ B) Evenness $(J) \times$ UGR (Wald: $\left.\chi_{(2)}^{2}=0.523 ; p=0.769\right)$; (C) Dominant species $(N d) \times \mathrm{UGR}$ (Wald: $\left.\chi_{(2)}^{2}=0.523 ; p=0.770\right)$. Black circles = old villas; Empty squares $=$ remaining green areas.
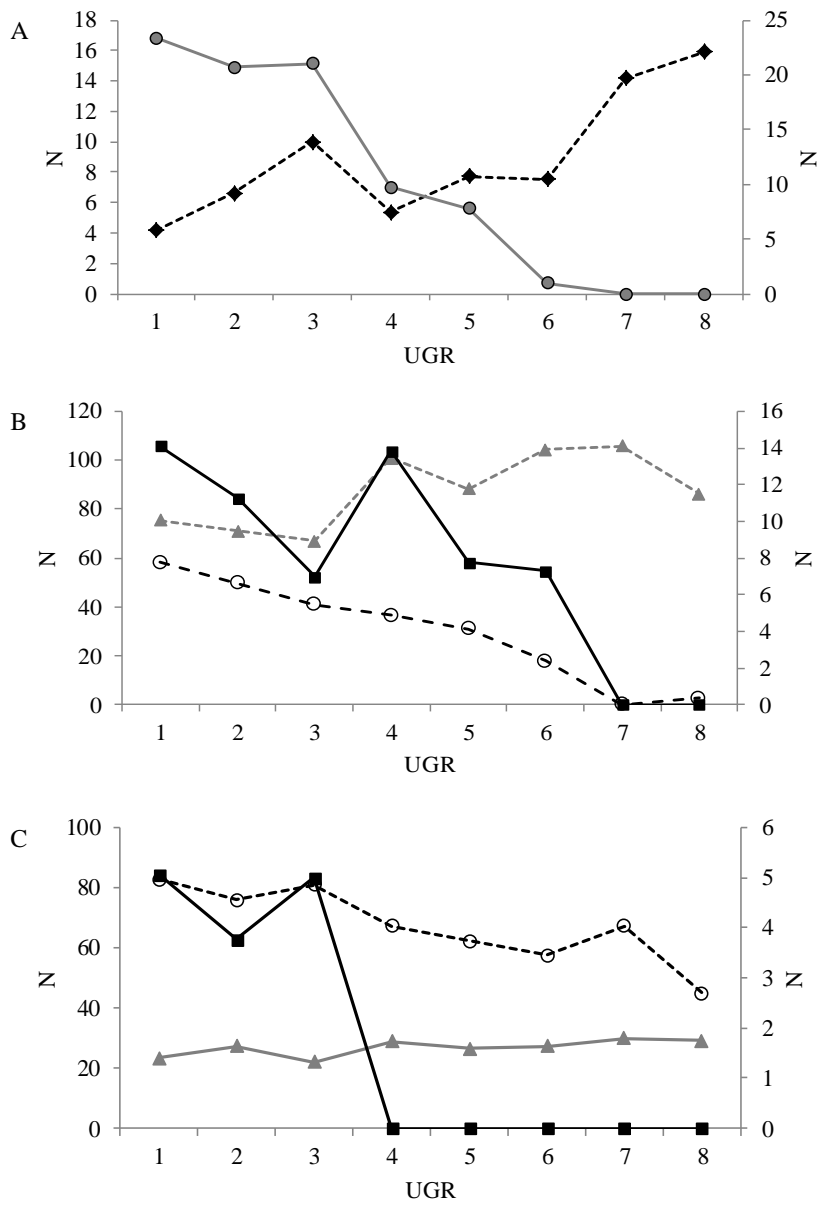

Figure 4. Different significant trends showed by functional groups belonging to the nesting (A), habitat (B), and feeding (C) functional groups in terms of absolute abundance along the eight urbanization gradient rings (1-8 rural to urban gradient). (A) - grey circles and continuous line: ground nesters (T; right $\mathrm{y}$-axis); black rhombuses and dotted line: artificial anthropic cavities nesters (CP; left y-axis). (B) - black squares and continuous line: open forest dwellers (FA) (left y-axis); grey triangles and dotted line: forest dwellers (F; left y-axis); empty circles and black dotted line: open habitat dwellers (A: right y-axis). (C) - black squares and continuous line: predators (P; right $\mathrm{y}$-axis); empty circles and black dotted line: granivorous (G; left y-axis); grey triangles and dotted line: omnivorous (O; left $\mathrm{y}$-axis).

sampling years) (Cignini and Zapparoli, 1996) accounts for 75 breeding species. If aquatic and nocturnal species are excluded and Apus spp. are counted as one species due to the difficulty in distinguishing them in flight, the checklists from the two studies are similar (66 - Cignini and Zapparoli, 1996 vs. 68 - present research). Particularly noteworthy from a faunistic and conservation viewpoint is the widespread observation of two breeding alien parrot species, Myiopsitta monachus and Psittacula krameri, not previously recorded, whose frequency of occurrence showed a significant positive relationship with the proximity to city centre. 

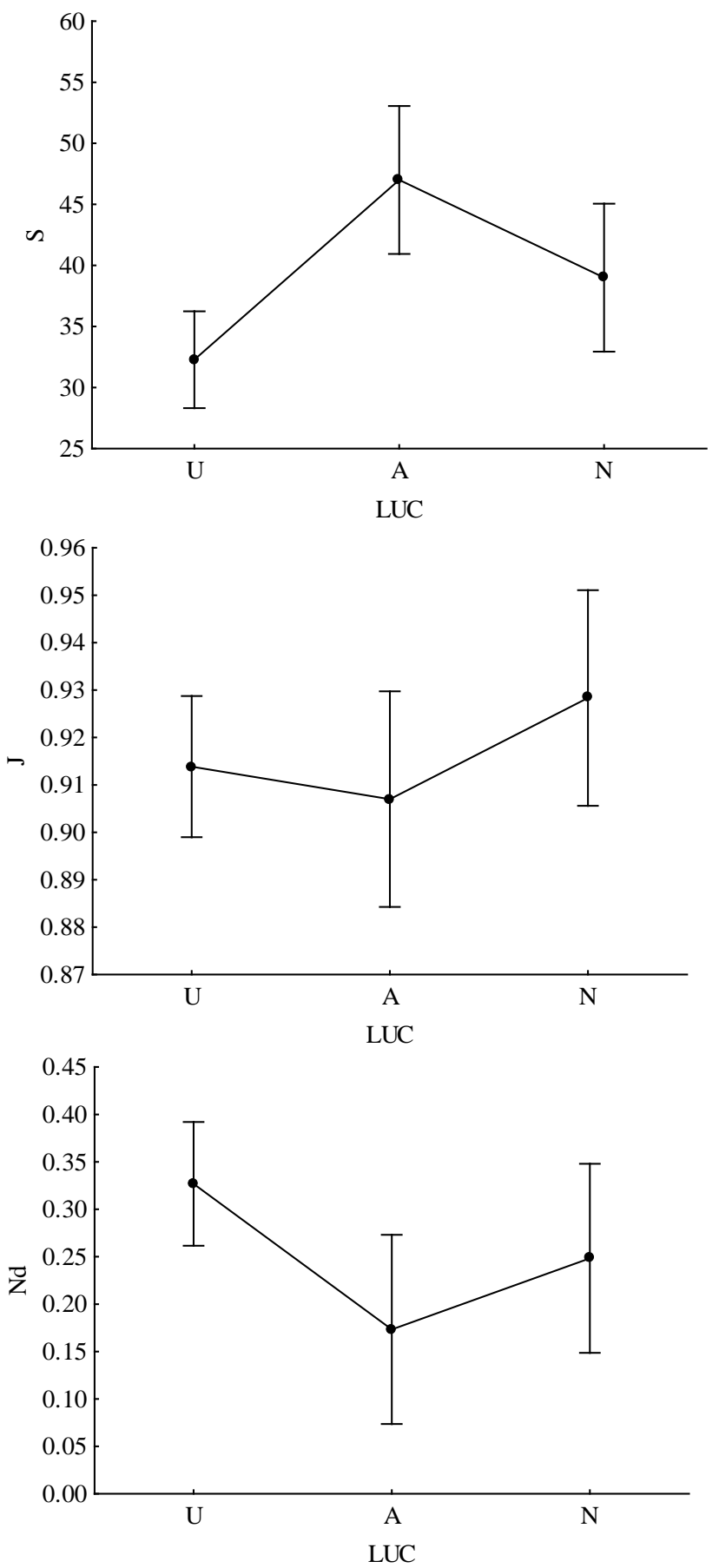

Figure 5. MANOVA plots illustrating average structural parameter values of bird communities for 13 selected land use categories belonging to urban (U), agricultural (A) and natural (N) habitats. Vertical bars denote 0.95 confidence intervals. Community parameter abbreviations: $S=$ species richness; $J=$ Evenness; $N d=$ dominant species.

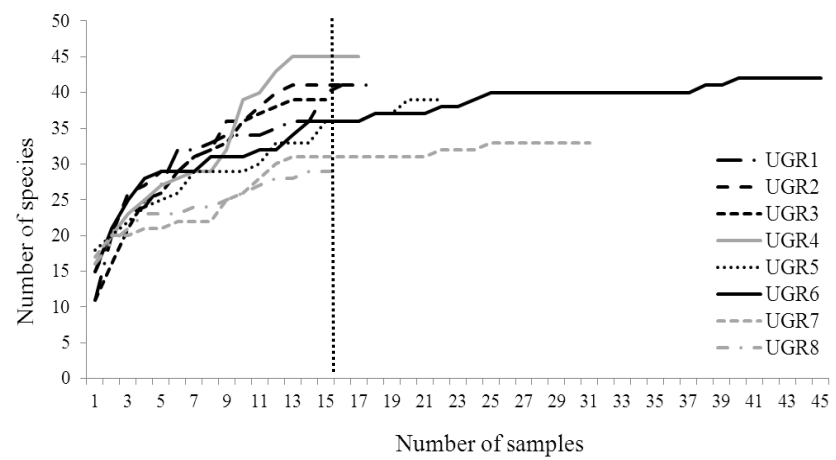

Figure A1. Accumulation curves elaborated for all the studied urbanization gradient rings (UGR). Vertical dotted line represents the minimum number of samplings $(N=15)$ shared by all the rings. Nearly all the accumulation curves rich the plateau value at sampling $N=15$.

Some previous studies carried out on birds in cities have found urbanization to have an overall negative effect upon bird communities, such as a reduction in both species richness and some specialised functional groups abundance (i.e. Blair, 1996; Bolger et al., 1997; Clergeau et al., 1998, 2006a; Jokimäki et al., 2005), whereas others have highlighted that local features (such as the reciprocal distribution of green areas or the vegetation diversity hosted by a given green area) may also influence bird communities and are of particular importance in estimating the likelihood of finding bird species (Clergeau et al., 2001; Melles et al., 2003). Our results showed that features at both landscape and local scales can explain bird community structures. Although nearly all the analysed bird community parameters, except the dominant species, showed a clear inverse relationship with increasing urbanization, the influence of urbanization features is not consistent with a negative effect on all the bird species and functional groups (as also revealed by Kark et al., 2007). In fact, the commonest and most widespread species, characterised by high ecological amplitude, took advantage of different levels of urbanization, so proving dominant in all the tested communities within all the study sectors and along the rural-urban gradient (i.e. T. merula, S. atricapilla, $C$. corone). A similar finding pertains at the functional group level. Many groups of species, e.g. ground and natural hole nesters (i.e. Alaudidae and Picidae), associated with specific land use features (i.e. pastures and forest cover, respectively) showed an overall rarity in all the study sectors. These patterns can be linked with the fact that when pristine habitat cover undergoes a significant reduction and modification, the species composition consequently changes and the communities become dominated by more "urban-adapted" (i.e. generalist/dominant) species, usually referable to the artificial anthropic cavities' nesting functional group and the omnivorous feeding functional group (Blair and Launer, 1997; Marzluff, 2001; Turner et al., 2004). 


\subsection{Local scale}

There is a widely observed reduction in species richness from peri-urban areas to the city centre as green areas proximal to the inner city deteriorate in habitat quality and take on a simplified vegetation structure (Clergeau et al., 1998, 2006a; Jokimäki and Huhta, 2000; but see McKinney, 2006 for the inverse pattern). Therefore, we could expect to observe a similar trend in species richness across our urbanization gradient.

In our study, at the point count station scale, bird species richness decreased with increasing urbanization following a unimodal pattern; in other words, the transition from agricultural to urbanized land use produces a decrease in the number of bird species with a peak of species richness at the gradient mid-point. The humpbacked relationship is one of the most analysed patterns in ecology (Graham and Duda, 2011). This pattern of a species richness trend along an urbanization gradient has been widely investigated in bird community studies (e.g. Blair, 1996, 1999; Blair and Johnson, 2008; Shwartz et al., 2008), this being potentially generated by an intermediate intensity, frequency, or duration of disturbance (intermediate disturbance hypothesis, - see Wilkinson, 1999) due to a suite of factors linked to urbanization. Alternatively it could be related to different factors, such as an increasing spatial heterogeneity in the middle of the gradient (Roxburgh et al., 2004), which in turn is linked in some way to the intermediate disturbance hypothesis and relative nonlinearity (Chesson, 2000). In our study system an increased spatial diversity in the middle of the gradient is clearly mirrored by the higher number of land use typologies found in the central UGRs in respect to those at both peripheral and central ends. However, at this stage we are unable to uniquely distinguish between these non-mutually exclusive hypotheses.

The species richness was positively influenced by natural land use when the old villas (the green areas represented mainly by human modified land use) are not considered. This could be explained by the fact that the old villas, by supporting a high number of bird species, likely reduced the gap between urban and natural land use categories as far as species richness is concerned. The distribution of land use among the study sectors influenced the species richness-natural land uses relationship. This effect is likely explained by a nonhomogeneous distribution of green areas (especially old villas are widespread in three out four sectors) among sectors.

Moreover, when all the land use typologies were taken into consideration together, species richness did not show a significant trend according to either the distance from the city centre or land use categories, but only became significant when the distance interacted with land use and when the old villas were removed from the analysis. In other words, the expected species richness decreased along with the distance from the periphery to the centre of the city (a crude and simplistic representation of the gradient) was disregarded by the peculiar habitat quality and distribution of large ( $>50$ hectares) historical villas within Rome.

\subsection{Landscape scale}

\subsubsection{Urbanization gradient rings (UGRs)}

The species richness estimated at the landscape scale showed no trend when correlated to the distance to the city centre, whereas this parameter was negatively affected by the urbanization gradient. The number of bird species was significantly influenced by both distance and urban gradient, showing a negative trend, when old villas were not considered in the analyses. Indeed, the location of large-sized remnant green areas dispersed along the studied gradient influences the bird species richness but not evenness or number of dominant species. These historical remnant fragments are widespread in inner Rome (from ring six to ring eight) and are usually managed with a view to conserving a section with centenary trees, while keeping smaller areas in a "wild" state with woods and Mediterranean maquis and shrubs (Sorace, 2001). The presence of a mixture of micro-habitats in urban parks enhances the richness and diversity of available resources. This allows a high species richness and bird density, so ensuring biodiversity "hot spots" within cities, particularly in the inner neighbourhoods where no other natural large-sized patches have been maintained due to urbanization (Blair, 1996; Fernández-Juricic, 2000; Croci et al., 2008; see Vignoli et al., 2009 for herpetofauna).

In contrast with species richness, the other community parameters showed significant links to both distance and the urbanization gradient, being negative for evenness and positive for the number of dominant species. Along urbanization gradients an alteration has often been observed, in terms of a simplification of the vegetation structure and stratification in most of the remnant patches with a cascade effect on bird assemblages: (i) loss of sensitive species (see below for functional groups), (ii) abundance decrease of non-generalist species due to elective habitat reduction, (iii) abundance increase of generalist species (urban exploiters), which become dominant in the assemblages (Clergeau et al., 2006a; Sorace and Gustin, 2009).

\subsubsection{Functional groups}

The analysis of functional group distribution along the study gradient provided detailed indications of how bird species assemblages sharing similar requirements can reveal contrasting patterns imperceptible when the community is studied as a whole. As regards to bird functional groups in the urban habitat, the literature already provides some detected patterns. Urbanization acts against high canopy and foliage exploiters and strongly favours ground feeding-granivorous and omnivorous species vs. aerial insectivores (decreasing due to the urban pollution). Likewise it favours cavity nesting species (especially those using anthropogenic cavities) vs. 
"ground nesters" (Lancaster and Rees, 1979; Beissinger and Osborne, 1982; Mills et al., 1989; Allen and O'Conner, 2000; Jokimäki et al., 2005; Chace and Walsh, 2006; Clergeau et al., 2006a). According to our analysis of nesting functional groups, the increased urbanization level clearly represents a detriment for the species nesting on the ground, this being likely due to nest predation and decreasing habitat quality and availability (Jokimäki et al., 2005). Ground nesting species are particularly sensitive to urbanization because, even if predation pressure by raptors is reduced in towns, they are likely affected by carrion crows (Corvus corone), a dominant species in urbanized habitats and a major avian nest predator (Andrén, 1992). Moreover, there are many generalist nest predators linked to human activities such as dogs, foxes and cats that may negatively affect the nesting opportunities for these species (Osborne and Osborne, 1980; Clergeau et al., 2006a; Sorace and Gustin, 2009). The beneficiaries of this situation are the artificial cavity breeders, which take advantage by colonizing patches in the inner city. In this regard, an important consideration is that the proximity of the buildings surrounding the green areas might favour species linked to these structures through nesting sites and perching opportunities rather than intrinsic characteristics of the patch itself (Clergeau et al., 2006a). The analysis of the habitat functional groups revealed that species related to open habitats sensu lato (intensive cereal cultivations, semi-natural pastures and bushy meadows) showed a clear reduction in total relative frequencies from external to internal UGRs. Also, two out of three open habitat sub-functional groups presented the same trend, evidencing an overall similar response to the degree of urbanization by functional groups with specific requirements in physionomic-structural features. Interestingly, the two functional groups linked to forested habitat showed two opposite trends: (i) a decrease in total frequency of species associated to open forest habitat and (ii) an increase in those linked to close forested habitats from external to internal urbanization rings. We interpreted both the observed trends as related to the property and the extent of the habitats surrounding the wooded areas within the fragment. In the city outskirts, green areas are typically urban-agricultural parks with wooded patches surrounded by wide cultivated fields or pasture. While in the city centre, in the patches with significant forest cover, the open-land habitats only border wide patches of woodland. Indeed, the wooded fragments sited at the periphery of the town likely match the ecological requirements for the species linked to open forest, whereas the species associated to closed forest find their elective habitat in the wooded patches in the inner city. As far as the feeding functional groups are concerned, we found two contrasting patterns shown by granivorous and predator groups on one side and omnivorous species on the other, the urbanization degree affecting the former functional groups negatively and the latter positively. Insectivorous species abundance did not correlate with the increasing urbanization. While for predators we have no comparable results coming from other studies, what was observed for the granivorous feeding group is opposite to the trend observed in previous studies (Kark et al., 2007; Blair and Johnson, 2008; Shwartz et al., 2008). In a real rural-urban gradient, as in our own study, it should not be surprising that the density of seed feeders decreases with the decline of cultivated fields, cereal cultures and non-intensive farming. As for insect feeders, our results apparently contrast with the significant decline with increasing urbanization previously been found by other authors (Chace and Walsh, 2006; Kark et al., 2007; Blair and Johnson, 2008; Shwartz et al., 2008), but match with the findings of Evans et al. (2011). It is likely that in the inner rings, the rich vegetation sheltered by the old villas provides a food resource for insectivorous species whose diet is based on ground and aerial insects.

Overall, different ecological bird categories (see Root, 1967) appear to be affected by urbanization in different ways. Birds of Rome appear to fall into three broad groups: urban avoiders (ground nesters, open habitat and open forest dweller species, predators and seed feeders), suburban adaptable (forest dweller species) and urban exploiters (artificial cavity nester and omnivorous species).

Moreover, our results showed that urban-rural gradients can be complex due to the interaction among various anthropogenic factors and between anthropogenic and natural variables. Although some of these interactions can be assessed qualitatively and quantitatively, additive and synergic effects are very difficult to detect or estimate (McDonnel and Pickett, 1990). Indeed, even if the environment is ordered in space (urbanization gradient) and the communities respond with variations in structure and composition ("gradient paradigm"; Whittaker, 1967), not all community parameters are affected in the same way or, indeed, may not be affected at all. Hence, for a comprehensive and thorough interpretation of these complex patterns, the use of multicommunity-parameter analyses is due.

\subsubsection{Land use categories}

The distribution of land use categories influenced all the measured community parameters. Overall the land use categories belonging to agricultural activities shown the highest assemblage parameter values. Particularly noteworthy is the high level of species richness and diversity showed by urbanized cultivation categories (UC50 and UC75: horticultures and other small-sized mixed cultivated green areas within the urban matrix). This demonstrates the importance of this type of land use in ensuring a variegated habitat for a diversified bird assemblage within the urban matrix. It is not surprising that natural land use category groups showed overall lower diversity metrics than agricultural ones; most farms in the study area adopt extensive methods of cultivation and maintain large portion of the fields with hedges, trees and shrubs, determining a high micro-habitat heterogeneity, which makes it possible to shelter diversified bird 
assemblages and conserve the species-specific key structure (Tews et al., 2004). Moreover, the influence of land use categories on avian community structure also revealed withinhabitat type variations along the urban gradient, with specific land use categories showing different patterns as for the community parameters: (i) natural habitats showed increasing dominant species and decreasing species richness with increasing urbanization and (ii) agricultural habitats presented a decreased evenness in the communities closed to the city centre. Hostetler and Knowles-Yanez (2002) found that land use did not correlate with bird community parameters for most of their studied species; they concluded, based on previous studies, that land cover is a better proxy for bird abundance than land use (for the different meanings of land cover and land use see the review by Comber, 2008). In fact, the study by Hostetler and Knowles-Yanez (2002) investigated the bird communities in a single town (Phoenix, Arizona, USA) and their results cannot be generalised. Since other recent papers have demonstrated the relationship between bird abundance and land use (Ortega-Álvarez and MacGregorFors, 2009; MacGregor-Fors et al., 2010; Suarez-Rubio et al., 2011; Siriwardena et al., 2012), our results contribute to the discovering of more generalizable patterns regarding the effect of land use on bird diversity.

\subsection{Conservation implications}

Our study is one of the few attempts in avian community ecology to combine the effect of urbanization gradient with that of specific land use typologies on bird assemblages and functional groups together. Our results suggest that the ruralurban gradient plays a major role in structuring bird communities (Clergeau et al., 2006a; McKinney, 2006). It is not the only factor affecting community parameters, however. The extent and distribution of land use categories along the rural-urban gradient is another factor influencing avian assemblages. The presence of historical villas also influences bird assemblage distribution, composition and richness, making it possible to preserve a high bird diversity even in inner city areas. Therefore, to guarantee bird conservation it is crucial to preserve the status of the large-sized green areas and to re-establish and/or enhance the habitat heterogeneity in those smaller remnant patches (natural or artificial) whose vegetation structure (stratification, tree species diversity) has been impoverished by anthropogenic factors (recreational use, commercial activity exploitation). The response to urbanization is functional group-specific (Kark et al., 2007); therefore, to understand the processes involved in community assembly and to propose the appropriate and effective conservation measures it is essential to identify the specific bird traits associated with sensitivity to urbanization (see Ewers and Didham, 2006).

Indeed, in the urban landscape, the green areas, particularly the largest patches, should serve as important components of local conservation strategies. Moreover, the key role played by the old villas in maintaining high biodiversity levels in the inner-city must be taken in account when it comes to regulating human use of these green areas, whether for recreation, sport or public entertainment. Overall, our results suggest that urbanized landscapes can support highly diverse bird assemblages and therefore support the efforts aimed at preserving the remaining patches in areas of high human population density (Pautasso et al., 2010).

Acknowledgements. We sincerely thank C. Battisti and L. Luiselli for suggestions on earlier drafts and two anonymous referees for their comments. We are indebted to Martin Bennet and Roger Federer (and of course to Federer's brilliant and promising scion Grigor Dimitrov) for the English revision of the final draft. L. Vignoli dedicates this paper to his friend Young Django (the " $D$ " is silent), who tragically died during a very fatigue field session.

Edited by: J. Stadler

Reviewed by: two anonymous referees

\section{References}

Alberti, M.: The effects of urban patterns on ecosystem function, Int. Regional Sci. Rev., 28, 168-192, 2005.

Aldrich, J. W. and Coffin, R. W.: Breeding bird populations from forest to suburbia after thirty-seven years, Amer. Birds, 34, 3-7, 1980.

Alldredge, M. W., Simons, T. R., and Pollock, K. H.: A field evaluation of distance measurement error in auditory avian point count surveys, J. Wildlife Manage., 71, 2759-2766, 2007.

Allen, A. P. and O'Conner, R. J: Hierarchical correlates of bird assemblage structure on northeastern USA lakes, Environ. Monit. Assess., 62, 15-35, 2000.

Andrén, H.: Corvid Density and Nest Predation in Relation to Forest Fragmentation: A Landscape Perspective, Ecology, 73, 794-804, 1992.

Barker, R. J. and Sauer, J. R.: Statistical aspects of point count sampling, in: Monitoring Bird Populations by Point Counts, edited by: Ralph, C. J., Sauer, J. R., and Droege, S., General Technical Report PSW-GTR-149, Pacific Southwest Research Station, Forest Service, US Department of Agriculture, Albany, CA, 125130, 1995.

Beissinger, S. R. and Osborne, D. R: Effects of urbanization on avian community organization, Condor, 84, 75-83, 1982.

Berland, A: Long-term urbanization effects on tree canopy cover along an urban-rural gradient, Urban Ecosys., 15, 721-738, doi:10.1007/s11252-012-0224-9, 2012.

Bibby, C. J. and Burgess, N. D.: Bird Census Techniques, Academic Press, London, 1992.

Blair, R. B: Land use and avian species diversity along an urban gradient, Ecol. Appl., 6, 506-519, 1996.

Blair, R. B.: Birds and butterflies along an urban gradient: surrogate taxa for assessing biodiversity?, Ecol. Appl., 9, 164-170, 1999.

Blair, R. B. and Johnson, E. M.: Suburban habitats and their role for birds in the urban-rural habitat network: Points of local invasion and extinction?, Landsc. Ecol, 23, 1157-1169, 2008. 
Blair, R. B. and Launer, A. E.: Butterfly diversity and human land use: species assemblages along an urban gradient, Biol. Conserv., 80, 113-125, 1997.

Blasi, C., Capotorti, G., Celesti-Grapow, L., Ercole, S., Filesi, L., Lattanzi, E., Michetti, L., Paolanti, M., and Tilia, A.: Land use types and vegetation maps of the Rome Municipality $1: 50,000$, Comune di Roma, Roma, 2001.

Bogosian, V., Hellgren, E. C., and Moody, R. W.: Assemblages of Amphibians, Reptiles, and Mammals on an Urban Military Base in Oklahoma, Southw. Natur, 57, 277-284, 2012.

Bolger, D. T., Scott, T. A., and Rotenberry, J. T.: Breeding bird abundance in an urbanizing landscape in coastal southern California, Conserv. Biol., 11, 406-421, 1997.

Buckland, S. T., Anderson, D. R., Burnham, K. P., Laake, J. L., Borchers, D. L., and Thomas, L.: Introduction to distance sampling, Oxford University Press, Oxford, 2001.

Burnham, K. P.: Summarizing remarks: Environmental influences, in: Estimating numbers of terrestrial birds, edited by: Ralph, C. J. and Scott, J. M., Stud. Avian Biol., 6, 324-325, 1981.

Cam, E., Nichols, J. D., Sauer, J. R., Hines, J. E., and Flather, C. H.: Relative species richness and community completeness: birds and urbanization in the mid-Atlantic states, Ecol. Appl., 10, 1196-1210, 2000.

Celesti Grapow, L.: Atlante della Flora di Roma (Atlas of the flora of Rome), Argos, Comune di Roma, Roma, 1995.

Chace, J. F. and Walsh, J. J.: Urban effects on native avifauna: a review, Landscape Urban Plan., 74, 46-69, 2006.

Chesson, P.: Mechanisms of maintenance of species diversity, Annu. Rev. Ecol. Syst., 31, 343-366, 2000.

Cignini, B. and Zapparoli, M.: Atlante degli uccelli nidificanti a Roma (Atlas of the breeding birds of Rome), Fratelli Palombi Editori, Roma, 1996.

Clergeau, P., Savard, J. P. L., Mennechez, G., and Falardeau, G.: Bird abundance and diversity along an urban-rural gradient: a comparative study between two cities on different continents, Condor, 100, 413-425, 1998.

Clergeau, P., Jokimaki, J., and Savard, J. P. L.: Are urban bird communities influenced by the bird diversity of adjacent landscapes?, J. Appl. Ecol., 38, 1122-1135, 2001.

Clergeau, P., Croci, S., Jokimäki, J., Kaisanlahti-Jokimäki, M. L., and Dinetti, M.: Avifauna homogenisation by urbanisation: Analysis at different European latitudes, Biol. Conserv., 127, 336344, 2006a.

Clergeau, P., Jokimäki, J., and Snep, R.: Using hierarchical levels for urban ecology, Trends Ecol. Evol., 21, 660-661, 2006b.

Comber, A. J.: Land Cover or Land Use?, J. Land Use Sci., 3, 199201, 2008.

Cramp, S.: The complete birds of the western Palaearctic, Optimedia, Oxford Univ. Press, Oxford, 1998.

Croci, S., Butet, A., Georges, A., Aguejdad, R., and Clergeau, P.: Small urban woodlands as biodiversity conservation hot-spot: a multi-taxon approach, Lands. Ecol., 23, 1171-1186, 2008.

Crooks, K. R., Suarez, A. V., and Bolger, D. T.: Avian assemblages along a gradient of urbanization in a highly fragmented landscape, Biol. Conserv., 115, 451-462, 2004.

Díaz, S. and Cabido, M.: Vive la différence: plant functional diversity matters to ecosystem processes, Trends Ecol. Evol., 16, 646-655, 2001.
Du Toit, M. J. and Cilliers, S. S.: Aspects influencing the selection of representative urbanization measures to quantify urban-rural gradients, Lands. Ecol., 26, 169-181, 2011.

Evans, K. L., Chamberlain, D. E., Hatchwell, B. J., Gregory, R. D., and Gaston, K. J.: What makes an urban bird?, Glob. Change Biol., 17, 32-44, doi:10.1111/j.1365-2486.2010.02247.x, 2011.

Ewers, R. M. and Didham, R. K.: Confounding factors in the detection of species responses to habitat fragmentation, Biol. Rev., 81, 117-142, 2006.

Faeth, S. H., Saari, S., and Bang, C.: Urban Biodiversity: Patterns, Processes and Implications for Conservation, eLS 2012, John Wiley \& Sons Ltd, Chichester, 2012.

Fernández-Juricic, E.: Bird community composition patterns in urban parks of Madrid: the role of age, size and isolation, Ecol. Res., 15, 373-383, 2000.

Fraterrigo, J. M. and Wiens, J. A.: Bird communities of the Colorado Rocky Mountains along a gradient of exurban development, Lands. Urban Plan., 71, 263-275, 2005.

French, D. D. and Picozzi, N.: "Functional groups" of bird species, biodiversity and landscapes in Scotland, J. Biogeogr., 29, 231259, 2002.

Fuller, R. J. and Langslow, D. R.: Estimating numbers of birds by point counts: how long should counts last?, Bird Study, 31, 195202, 1984.

Gagné, S. A. and Fahrig, L.: Do birds and beetles show similar responses to urbanization?, Ecol. Appl., 21, 2297-2312, 2011.

Garaffa, P. I., Filloy, J., and Bellocq, M. I.: Bird community responses along urban-rural gradients: Does the size of the urbanized area matter?, Lands. Urban Plan., 90, 33-41, 2009.

Gotelli, N. J. and Entsminger G. L.: EcoSim: Null models software for ecology. Version 7.0. Acquired Intelligence Inc. \& Kesey-Bear, http://homepages.together.net/ gentsmin/ecosim. htm, 2001.

Graham, J. H. and Duda, J. J.: The humpbacked species richnesscurve: a contingent rule for community ecology, Int. J. Ecol., 2011, 1-15, doi:10.1155/2011/868426, 2011.

Hostetler, M. and Knowles-Yanez, K.: Land use, scale, and bird distributions in the Phoenix metropolitan area, Lands. Urban Plan., 62, 55-68, 2002.

Johnson, D. H.: In defense of indices: the case of bird surveys, J. Wildlife Manage., 72, 857-868, 2008.

Jokimäki, J. and Huhta, E.: Artificial nest predation and abundance of birds along an urban gradient, Condor, 102, 838-847, 2000.

Jokimäki, J., Kaisanlahti-Jokimäki, M. L., Sorace, A., Fernández Juricic, E., Rodriguez Prieto, I., and Jimenez, M. D.: Evaluation of the "safe-nesting zone" hypothesis across an urban gradient: a multi-scale study, Ecography, 28, 59-70, 2005.

Kark, S., Iwaniuk, A., Schalimtzek, A., and Banke, E.: Living in the city: can anyone become an "urban exploiter"?, J. Biogeogr., 34, 638-651, 2007.

Lancaster, R. K. and Rees, W. E.: Bird communities and the structure of urban habitats, Canad. J. Zool., 57, 2358-2368, 1979.

Llop, E., Pinho, P., Matos, P., Pereira M. J., and Branquinho, C.: The use of lichen functional groups as indicators of air quality in a Mediterranean urban environment, Ecol. Indic., 13, 215-221, 2012.

Lloyd, M. and Ghelardi, R. J.: A table for calculating the equitability component of species diversity, J. Anim. Ecol., 33, 217-225, 1964. 
MacGregor-Fors, I., Morales-Pérez, L., and Schondube, J. E.: Migrating to the city: responses of neotropical migrant bird communities to urbanization, Condor, 112, 711-717, 2010.

Marzluff, J. M.: Worldwide urbanization and its effects on birds, in: Avian Ecology in an urbanizing World, edited by: Marzluff, J. M., Bowman, R., and Donnelly, R., Kluwer Academic, Norwell, Massachusetts, USA, 19-47, 2001.

Matson, P.: The use of urban gradients in ecological studies, Ecology, 71, p. 1231, 1990.

McDonnell, M. J. and Hahs, A. K.: The use of gradient analysis studies in advancing our understanding of the ecology of urbanizing landscapes: current status and future directions, Land. Ecol., 23, 1143-1155, 2008.

McDonnell, M. J. and Pickett, S. T. A.: The study of ecosystem structure and function along urban-rural gradients: an unexploited opportunity for Ecology, Ecology, 71, 1232-1237, 1990.

McDonnell, M. J., Pickett, S. T. A., and Pouyat, R. B.: The application of the ecological gradient paradigm to the study of urban effects, in: Humans as Components of Ecosystems, edited by: McDonnell, M. J. and Pickett, S. T. A., Springer-Verlag, New York, USA, 175-189, 1993.

McDonnell, M. J., Pickett, S. T. A., Groffman, P., Bohlen, P., Pouyat, R. V., Zipperer, W. C., Parmelee, R. V., Carreiro, M. M., and Medley, K.: Ecosystem processes along an urban-rural gradient, Urban Ecosys., 1, 21-36, 1997.

McKinney, M. L.: Urbanization as a major cause of biotic homogenization, Biol. Conserv., 127, 247-260, 2006.

Melles, S., Glenn, S., and Martin, K.: Urban bird diversity and landscape complexity. Species-environment associations along a multiscale habitat gradient, Conserv. Ecol., 7, 271-279, 2003.

Mills, G. S., Dunning Jr, J. B., and Bates, J. M.: Effects of urbanization on breeding bird community structure in south western desert habitats, Condor, 91, 416-428, 1989.

Ortega-Álvarez, R. and MacGregor-Fors, I.: Living in the big city: Effects of urban land-use on bird community structure, diversity, and composition, Landsc. Urban Plan., 90, 189-195, 2009.

Osborne, P. and Osborne, L.: The contribution of nest site characteristics to breeding-success among Blackbirds Turdus merula, Ibis, 122, 512-517, 1980.

Pautasso, M., Böhning-Gaese, K., Clergeau, P., Cueto, V. R., Dinetti, M., Fernández-Juricic, E., Kaisanlahti-Jokimäki, M.-L., Jokimäki, J., McKinney, M. L., Sodhi, N. S., Storch, D., Tomialojc, L., Weisberg, P. J., Woinarski, J., Fuller, R. A., and Cantarello, E.: Global macroecology of bird assemblages in urbanized and semi-natural ecosystems, Global Ecol. Biogeogr., 20, 426-436, 2010.

Pellissier, V., Cohen, M., Boulay, A., and Clergeau, P.: Birds are also sensitive to landscape composition and configuration within the city centre, Landsc. Urban Plan., 104, 181-188, 2012.

Petchey, O. L., Hector, A., and Gaston, K. J.: How do different measures of functional diversity perform?, Ecology, 85, 847-857, 2004.

Ricotta, C., Celesti-Grapow, C., Avena, G., and Blasi, C.: Topological analysis of the spatial distribution of plant species richness across the city of Rome (Italy) with the echelon approach, Landsc. Urban Plan., 57, 69-76, 2001.
Root, R. B.: The Niche Exploitation Pattern of the Blue-Gray Gnatcatcher, Ecol. Monogr., 37, 317-350, doi:10.2307/1942327, 1967.

Roxburgh, S. H., Shea, K., and Wilson, J. B.: The intermediate disturbance hypothesis: patch dynamics and mechanisms of species coexistence, Ecology, 85, 359-371, 2004.

Sattler, T., Duelli, P., Obrist, M. K., Arlettaz, R., and Moretti, M.: Response of arthropod species richness and functional groups to urban habitat structure and management, Lands. Ecol., 25, 941954, 2010.

Shwartz, A., Shirley, S., and Kark, S.: How do habitat variability and management regime shape the spatial heterogeneity of birds within a large Mediterranean urban park?, Landsc. Urban Plan., 84, 219-229, 2008.

Simberloff, D. and Dayan, T.: The functional group concept and the structure of ecological communities, Annu. Rev. Ecol. Syst., 22, 115-143, 1991.

Siriwardena, G. M., Cooke, I. R., and Sutherland, W. J.: Landscape, cropping and field boundary influences on bird abundance, Ecography, 35, 162-173, 2012.

Sorace, A.: Value to wildlife of urban-agricultural parks: a case study from Rome urban area, Environ. Manage., 28, 547-560, 2001.

Sorace, A. and Gustin, M.: Bird species of conservation concern along urban gradients in Italy, Biodiv. Conserv., 19, 205-221, 2009.

Sorace, A., Gustin, M., Calvario, E., Ianniello, L., Sarrocco, S., and Carere, C.: Assessing bird communities by point counts: repeated sessions and their duration, Acta Ornithol., 35, 197-202, 2000.

Statsoft Inc.: STATISTICA (data analysis software system), version 8.0, Statsoft Inc., Tulsa, Oklaoma, 2008.

Strohbach, M. W., Haase, D., and Kabisch N.: Birds and the city: urban biodiversity, land use, and socioeconomics, Ecol. Soc., 14, 31, http://www.ecologyandsociety.org/vol14/iss2/art31/, 2009.

Suarez-Rubio, M., Leimgruber, P., and Renner, S. C.: Influence of exurban development on bird species richness and diversity, J. Ornith., 152, 461-471, 2011.

Tabachnick, B. G. and Fidell, L. S.: Using multivariate statistics, 4th Edn., Allyn and Bacon, Boston, 2001.

Taffon, D. and Battisti, C.: Breeding bird communities and ecotope niche breadth of the Species in a heterogeneous landscape of Central Italy, Riv. Ital. Ornitol., 75, 129-139, 2006.

Tews, J., Brose, U., Grimm, V., Tielbörger, K., Wichmann, M. C., Schwager, M., and Jeltsch, F.: Animal species diversity driven by habitat heterogeneity/diversity: the importance of keystone structures, J. Biogeogr., 31, 79-92, 2004.

Tilman, D.: Functional diversity, in: Encyclopedia of Biodiversity, edited by: Levin, S. A., Vol. 5, Academic Press, New York, 2001.

Turner, W. R., Nakamura, T., and Dinetti, M.: Global urbanization and the separation of humans from nature, Bioscience, 54, 585590, 2004.

Vignoli, L., Mocaer, I., Luiselli, L., and Bologna, M. A.: Can a large metropolis sustain complex herpetofauna communities? An analysis of green space areas suitability in Rome, Anim. Conserv., 12, 456-466, 2009.

Whittaker, R. H.: Gradient analysis of vegetation, Biol. Rev., 42, 207-264, 1967. 
Wiens, J. A.: The Ecology of Bird Communities 1: foundation and patterns, Cambridge University Press, Cambridge, 1997.
Wilkinson, D. M.: The disturbing history of intermediate disturbance, Oikos, 84, 145-147, 1999. 